\title{
TOWARDS A SYNECOLOGICAL FRAMEWORK FOR SYSTEMATIC CONSERVATION PLANNING
}

\author{
JOAQUÍN HORTAL \\ Dpto. Biodiversidad y Biología Evolutiva, Museo Nacional de Ciencias Naturales (CSIC), 28006 \\ Madrid, Spain, Center for Macroecology, Institute of Biology, University of Copenhagen, 2100 \\ Copenhagen O, Denmark, and Depto. Ciências Agrárias - CITA-A, Universidade dos Açores, \\ 9700-851 Angra do Heroísmo, Terceira, Azores, Portugal \\ E-mail: jhortal@mncn.csic.es
}

AND

JORGE M. LOBO

Dpto. Biodiversidad y Biología Evolutiva, Museo Nacional de Ciencias Naturales (CSIC), Madrid 28006, Spain

E-mail: mcnj117@mncn.csic.es

\begin{abstract}
Biodiversity conservation design, though difficult with fragmentary or insufficient biological data, can be planned and evaluated with several methods. One of them, the complementarity criterion, is commonly used to account for the distributions of a number of species (i.e., an autoecological approach). At the same time, the patchiness and spatial bias of available distribution data has also been dealt with through distribution modelling. However, both the uncertainty of the ranges estimated and the changes in species' distributions in response to changing climates, limit the potential of single-species distributions as the biodiversity attribute to be used in complementarity strategies. Several technical and theoretical advantages of composite biodiversity variables (i.e., a synecological approach) may, however, make them ideal biodiversity indicators for conservation area selection. The drawbacks associated with current biodiversity data are discussed herein, along with the possible advantages and disadvantages of conservation planning through a synecological or autoecological approach.
\end{abstract}

Key words. - biodiversity, complementarity, conservation biogeography, predictive modelling, climate change, surrogacy, emergent properties, Systematic Conservation Planning

Conservation Biogeography has recently been defined as "the application of biogeographical principles, theories, and analyses, being those concerned with the distributional dynamics of taxa individually and collectively, to problems concerning the conservation of biodiversity" (Whittaker et al. 2005). Here, the phenomenon of biodiversity at its whole width becomes the central target for conservation from a biogeographic perspective. However, current knowledge of biodiversity patterns and processes is not reliable enough for the models and scenarios needed for conservation policy decisions (see discussion in Whittaker et al. 2005). Such drawback has given rise to much debate as to what to protect, how to deal with available data insufficiency by means of surrogacy, and how to include ecosystem processes and natural services in Systematic Conservation Planning processes (see, e.g., Brooks et al. 2004a,b; Molnar et al. 2004; Higgins et al. 2004; Cowling et al. 2004; Pressey 2004, and references therein). Conservation biology needs a solid framework from which to work with the current fragmentary state of biodiversity data, while at 


\section{HoRTAL AND LOBO - SYNECOLOGICAL CONSERVATION FRAMEWORK}

the same time addressing the urgent need for a 'evaluation scheme', whereby conservation values can be input to the decision-making process (see Green et al. 2005 for such a scheme).

Whittaker and collaborators (2005) identify four inter-related Conservation Biogeography weaknesses: i) inadequacies in taxonomic and distribution data; ii) spatial and temporal scale dependency; iii) effects of model structure and parameterization and iv) inadequacies of theory. This work aims to develop the basis for a framework to deal with the first of the above-mentioned weaknesses (and partly accounting for the latter) in the sub-discipline of Systematic Conservation Planning (Margules and Pressey 2000). Leaving apart the less effective expert assessment (although the gains it provides should be integrated in conservation planning; see Cowling et al. 2003a), three approaches could be used as a basis for Systematic Conservation Planning schemes:

- The environment-based approach -- use environmental variation as a biodiversity descriptor.

- The autoecological approach (herein autoecology for short) -- gather observed or predicted distribution information for a great number of species, and use them as surrogates of overall diversity.

- The synecological approach (herein synecology) -- use composite biodiversity variables (i.e. synecological variables; e.g., species richness, rarity, endemism, community composition, etc.), either observed or estimated, to describe the whole patterns of biodiversity variation.

Considerable effort would be required to gather the amount of information needed for a reliable use of the autoecology approach. Therefore, as environmental information is more readily available, many authors favor the environment-based approach, which has been used during the development of several successful coarse-scale conservation schemes (e.g., the IUCN-WPCA reserve network approaches of the 1970s and 1980s; MacKinnon and MacKinnon 1986a,b; MacKinnon et al. 1986). However, environmental variation is just a surrogate for biodiversity, rather than a conservation target. Therefore, the drawbacks of the environmentbased approach should better be overcome using biodiversity data, which is a true conservation target itself.

From the approaches based on biodiversity data, the autoecological has been the most used, in spite of presenting practical and theoretical problems that could hamper its reliability (see below). A mixed approach combining autoecology and synecology could be using together biological and environmental data to model the distribution of the species of interest, and then aggregate their predictions to construct biodiversity variables, or use them for complementarity analyses (see, e.g., RojasSoto et al. 2003 or Ferrier and Guisan 2006; A. Lira-Noriega et al. unpubl.). Such approach lies under the assumption that errors in the predictions of the distributions of a number of species will minimize if they are used altogether. We here propose that the effort required in the drawing up of biogeography conservation schemes could be minimized, and the process simplified, by the direct gathering (and use) of synecological information instead of autoecological one. We examine the drawbacks associated with the current state of biodiversity data and discuss the technical and theoretical advantages of using synecological variables in Systematic Conservation Planning (see Box 1).

\section{GEOGRAPHIC REPRESENTATION OF BIODIVERSITY}

Biodiversity is a heterogeneous concept accounting for the multi-faceted, continuous variability of life, from genes to ecosystems. However, even though recent proposals 


\section{HORTAL AND LOBO - SYNECOLOGICAL CONSERVATION FRAMEWORK}

Box 1. Schematic SWOT Analysis for the three Systematic Conservation Planning approaches discussed: environment-based (E), autoecology (A) and synecology (S) (see Introduction for definitions). Tables on the right present the relevant characteristics of each approach. Strengths (S) and Weaknesses (W) are structural characteristics, and are intended as not to change in the short and/or medium-term. On the contrary, Opportunities $(\mathrm{O})$ and Threats $(\mathrm{T})$ are suited to the current status of the theoretical and practical knowledge on biodiversity and conservation fields, and could change in the near future. Items are numbered according to the approach they pertain (E, A, S), and the kind of characteristic they are (S, W, O and T) (e.g., ES1). SWOT analysis is based on studying the relevant combinations of $\mathrm{S}, \mathrm{W}, \mathrm{O}$ and $\mathrm{T}$ items inside of each approach through a TWOS matrix (matrices placed on the left), to identify its main drawbacks and advantages (see Dyson and O'Brien 1998 and Dyson 2004 for further reviews on the method). In addition to the TWOS matrices, we identify i) the structural conflicts between Strengths and Weaknesses (represented over the TWOS matrices), and ii) current limitations to Opportunities caused Threats (i.e., the state-of-the-art) (represented below TWOS matrices).

\begin{tabular}{|c|c|c|c|c|}
\hline \multicolumn{5}{|c|}{ E. environment-based approach } \\
\hline \multirow{3}{*}{$\begin{array}{l}\text { Strengths } \\
\text { ES1.Rapid mapping techniques } \\
\text { ES2.Information availability (GIS and } \\
\text { remote sensing) } \\
\text { ES3.Fine-grain geographic resolution }\end{array}$} & \multirow{3}{*}{$\begin{array}{l}\text { Weaknesses } \\
\text { EW1.Not a true conservation target } \\
\text { (surrogate) } \\
\text { EW2.Land classifications } \rightarrow \text { Abstract } \\
\text { human constructs }\end{array}$} & \multicolumn{3}{|c|}{$\begin{array}{l}(\mathrm{ES} 1+\mathrm{ES} 2+\mathrm{ES} 3) \mathrm{EW} 1 \\
(\mathrm{ES} 1+\mathrm{ES} 2) \mathrm{EW} 2\end{array}$} \\
\hline & & $\mathbf{O}$ & $(\mathrm{ES} 1+\mathrm{ES} 2) \times \mathrm{EO} 1$ & $\mathrm{EW} 1 \mathrm{x}(\mathrm{EO} 1+\mathrm{EO} 2)$ \\
\hline & & & $(\mathrm{ES} 1+\mathrm{ES} 2) \mathrm{xEO} 2$ & EW1xEO3 \\
\hline \multirow{6}{*}{$\begin{array}{l}\text { Opportunities } \\
\text { EO1.Ecosystem representation } \\
\text { EO2.Vegetation type representation } \\
\text { EO3.Ecological processes } \\
\text { representation } \\
\text { EO4.Species distribution } \\
\text { representation (relationship with } \\
\text { environment) }\end{array}$} & \multirow{6}{*}{$\begin{array}{l}\text { Threats } \\
\text { ET1.Lack of knowledge of the } \\
\text { relationship between land classes and } \\
\text { biodiversity variations } \\
\text { ET2.Risk of exclusive use of surrogacy } \\
\text { due to information easy availability }\end{array}$} & & ES3xEO2 & EW1xEO4 \\
\hline & & & $(\mathrm{ES} 1+\mathrm{ES} 2) \times \mathrm{EO} 3$ & EW2xEO3 \\
\hline & & & (ES1+ES2)XEO4 & EW2XEO4 \\
\hline & & $\mathbf{T}$ & $\begin{array}{l}\text { (ESI+ES2)xET1 } \\
(\mathrm{ES} 1+\mathrm{FS} 2) \times \mathrm{FT} 2\end{array}$ & $\begin{array}{l}\text { EW1xET2 } \\
\text { FW2xFT1 }\end{array}$ \\
\hline & & (FO & $\begin{array}{l}\text { (ESI+ES2)XE12 } \\
\text { (ES }\end{array}$ & \\
\hline & & & & \\
\hline
\end{tabular}

\begin{tabular}{|c|c|c|c|c|}
\hline \multicolumn{5}{|l|}{ A. autoecology approach } \\
\hline $\begin{array}{l}\text { Strengths } \\
\text { AS1.True conservation target }\end{array}$ & $\begin{array}{l}\text { Weaknesses } \\
\text { AW1.Incomplete information }\end{array}$ & \multicolumn{3}{|c|}{$\begin{array}{l}\text { (AS1+AS2)x(AW1+AW2+AW3+AW4) } \\
\text { AS3x(AW1+AW2+AW3) }\end{array}$} \\
\hline AS2.True biodiversity representation & AW2.Taxonomically biased information & & $\mathbf{S}$ & W \\
\hline $\begin{array}{l}\text { AS3.Representation of key species } \\
\text { important for ecosystem processes }\end{array}$ & $\begin{array}{l}\text { AW3.Geographically biased information } \\
\text { AW4.High amount of variables } \\
\text { (species) } \\
\text { AW5.Represents only patterns, not } \\
\text { processes }\end{array}$ & $\mathbf{O}$ & $\begin{array}{c}(\mathrm{AS} 1+\mathrm{AS} 2) \times \mathrm{AO} 1 \\
(\mathrm{AS} 1+\mathrm{AS} 2) \times \mathrm{XO} 2 \\
\mathrm{AS} 3 \times \mathrm{AO} 1 \\
\mathrm{AS} 3 \times \mathrm{AO} 2 \\
\mathrm{AS} 3 \mathrm{xAO} 3 \\
\end{array}$ & $\begin{array}{c}\text { AW1x(AO1+AO2) } \\
\text { AW2xAO1 } \\
\text { AW3x(AO1+AO2) } \\
\text { AW5xAO3 }\end{array}$ \\
\hline $\begin{array}{l}\text { Opportunities } \\
\text { AO1.Development of GBIF and other } \\
\text { biodiversity databases } \\
\text { AO2.Predictive modelling } \\
\text { AO3.Good knowledge on population } \\
\text { biology }\end{array}$ & $\begin{array}{l}\text { Threats } \\
\text { AT1.Lack of taxonomic work } \\
\text { AT2.Model error aggregation } \\
\text { AT3.Drawbacks for the use of rare } \\
\text { species } \\
\text { AT4.Fragmentary knowledge of the } \\
\text { relationship between key species and } \\
\text { ecosystem processes }\end{array}$ & \multicolumn{3}{|c|}{$\begin{array}{l}\text { AO1xAT1 } \\
\text { AO2x(AT2,AT3) } \\
\text { AO3xAT4 }\end{array}$} \\
\hline
\end{tabular}

\begin{tabular}{|c|c|c|c|c|}
\hline \multicolumn{5}{|l|}{ S. synecology approach } \\
\hline $\begin{array}{l}\text { Strengths } \\
\text { SS1.True conservation target }\end{array}$ & $\begin{array}{l}\text { Weaknesses } \\
\text { SW1.Incomplete information }\end{array}$ & \multicolumn{3}{|c|}{$\begin{array}{l}\text { (SS1+SS2)x(SW1+SW2+SW3) } \\
(\mathrm{SS} 3, \mathrm{SS} 4, \mathrm{SS} 5) \times(\mathrm{SW} 1+\mathrm{SW} 2+\mathrm{SW} 3)\end{array}$} \\
\hline SS2.True biodiversity representation & SW2.Taxonomically biased information & & $\mathbf{S}$ & $\mathbf{W}$ \\
\hline $\begin{array}{l}\text { SS3.Use of rare species } \\
\text { SS4.Reduced number of variables } \\
\text { SS5.Representation of emergent } \\
\text { processes }\end{array}$ & SW3.Geographically biased information & \multirow[t]{2}{*}{$\mathbf{O}$} & $\begin{array}{l}\text { (SS1+SS2)xSO1 } \\
(\mathrm{SS} 1+\mathrm{SS} 2) \mathrm{xSO} 3 \\
\mathrm{SS} 2 \mathrm{xSO} \\
\mathrm{SS} 3 \mathrm{xSO} 1\end{array}$ & $\begin{array}{c}\mathrm{SW} 1 \mathrm{x}(\mathrm{SO} 1+\mathrm{SO} 2+\mathrm{SO} 3) \\
\mathrm{SW} 2 \mathrm{x}(\mathrm{SO} 1+\mathrm{SO} 2) \\
\mathrm{SW} 3 \mathrm{x}(\mathrm{SO} 1+\mathrm{SO} 2+\mathrm{SO} 3)\end{array}$ \\
\hline Opportunities & Threats & & $\begin{array}{c}\mathrm{SS} 3 \mathrm{xSO} 2 \\
\mathrm{SS} 4 \mathrm{x}(\mathrm{SO} 2+\mathrm{SO} 3)\end{array}$ & \\
\hline $\begin{array}{l}\text { biodiversity databases } \\
\text { SO2.Variables can be estimated locally } \\
\text { SO3.Predictive modelling }\end{array}$ & $\begin{array}{l}\text { ST2.Partial knowledge of the } \\
\text { relationship between diversity and } \\
\text { ecosystem processes }\end{array}$ & $\begin{array}{r}\mathbf{T} \\
\text { SO1 }\end{array}$ & $\begin{array}{rr}\text { SS1xST1 } \\
& \text { SS5xST2 } \\
\text { ST1 } & \end{array}$ & $(\mathrm{SW} 1, \mathrm{SW} 2) \mathrm{xST} 1$ \\
\hline
\end{tabular}




\section{HORTAL AND LOBO - SYNECOLOGICAL CONSERVATION FRAMEWORK}

promise progress in assessing reductions in the rate of biodiversity loss (Scholes and Biggs 2005), information on genetic and population diversity is still grossly insufficient for conservation purposes, while that on the higher level (the species level) is fragmentary and biased (Gewin 2002). Biogeography-based conservation planning makes use of only those biodiversity features that can be mapped (Brooks et al. 2004a). As mapping and measuring ecological processes are still in their infancy (Cowling et al. 1999), most biogeography conservation efforts have targeted either (i) the observed or predicted pattern of species variation, or (ii) abiotic surrogates able to describe such a pattern. Whilst the former makes use of either species distribution data (autoecology approach) or synecological variables (synecology approach) as targets, abiotic surrogacy has relied on environmental variation as a well-known surrogate of biodiversity variation (the environment-based approach), employing either continuous environmental variation data (see e.g. Faith and Walker 1996a; Ferrier 2002; Venevsky and Venevskaia 2005) or land class data (land types sensu Pressey 2004). However, most former Systematic Conservation Planning applications have been academic rather than practical, being the results of area selection methods generally ignored by conservation planners (Prendergast et al. 1999; Cabeza and Moilanen 2001; but see Pressey and Cowling 2001; Cowling et al. 2003b; or Airame et al. 2003). Given the foregoing, Conservation Biogeography during the coming decades should strive to reconcile the need for a 'great synthesis,' to be presented as a unitary front to society and layman, with the possible scepticism that might arise from rapid science-based decision-taking in a field still in its infancy (Whittaker et al. 2005).

\section{Species or environment data?}

The long-latent disagreement over the superiority of either species or environment information, for both planning and for measuring the success of conservation efforts, has recently figured in debate (Araújo et al. 2004a; Brooks et al. 2004a,b; Cowling et al. 2004; Faith et al. 2004; Higgins et al. 2004; Molnar et al. 2004; Pressey 2004), although its origin can be traced back to the approaches that preceded recent Systematic Conservation Planning framework (see, e.g., Dasmann 1972; MacKinnon et al. 1986).

Those that favor the species-based approach claim that broad-scale biodiversity attributes such as land types or habitats are abstract and subjective human constructs; that environmental diversity does not necessarily reflect species diversity (Araújo et al. 2001); and that species should be the main unit of biodiversity (Wilson 2002). They argue that more taxonomic and distribution information should be gathered, that available information on species should be used (Rodrigues et al. 2003), and that geographical data of species distribution should be improved through the use of environmental variables to generate coherent distribution hypothesis. They maintain that while environment data and land classifications are important, these should be used just to upgrade the reliability of species data, not as conservation targets themselves (Brooks et al. 2004b).

On the other hand, defenders of the environment-based approach assert that conservation planning must also represent such other biodiversity attributes as land types, habitats or ecological processes; that ecosystems within species-poor areas may be crucial regarding the goods and services needed for nature functioning (Kareiva and Marvier 2003); and that lack of reliability is the main impediment to the use of species data (Pressey 2004).

In addition, other authors suggest that the use of broad-scale biodiversity attributes can facilitate the study of the most poorlyunderstood species and assemblages, such as invertebrates (Ward et al. 1999; Mac Nally et 
al. 2002), and that strategy should concentrate not on pattern but on processes. More information should be gathered on the ecological role of species, and their relevance in nutrient cycles and energy flows (Kareiva and Marvier 2003) and population size should be taken into consideration in the design of conservation strategies. Unfortunately for this argument, the relevance of species in ecological processes is no better understood than is species distribution.

A reconciliation of these apparently opposing arguments would entail that both environment and species data are necessary components of conservation assessment (Noss 1987; Clark and Slusher 2000; Faith and Ferrier 2002; Ferrier 2002; Ferrier et al. 2002b; Cowling et al. 2004; Higgins et al. 2004). Conservation decisions still have to be made in spite of bias and gaps in species information. Methods incorporating both types of data would establish promising conservation strategies (Ward et al. 1999; Cowling et al. 2003b; Lombard et al. 2003), while using a complete and complementary set of biodiversity surrogates would guarantee a better selection (Pressey 2004). Therefore, available taxonomic and distribution information should be combined with environment, land type and vegetation data to take advantage of advances in predictive modelling. Such a framework does not need to include the assumption that environment data by itself represents biodiversity variation (Wessels et al. 1999; Araújo et al. 2001; Pharo and Beattie 2001; Cushman and McGarigal 2002; Mac Nally et al. 2002; Lombard et al. 2003; Oliver et al. 2004; Su et al. 2004), but rather that environmental characteristics, combined with available species distribution information, should improve such data.

As both species and environment data are relevant, their respective contribution to conservation planning should depend on their quality and amount. However, in the case where both types of information are available, which should be considered more meaningful? Unfortunately, the available information on the whole biodiversity "agents" (species) has often been ignored in the design of protection strategies (see, e.g., European Nature 2000 Network ${ }^{1}$ ). Such a situation should be corrected, as the species are true conservation targets. As Brooks et al. (2004b) argued, there is a risk that conservation policies may be based on rapidly-obtained remote-sensing data and computer models, and may not incorporate the species data that could ensure the success of conservation decisions. Therefore, both species data and effective species-based methodologies should be put together on the table.

Could available species data account for biodiversity variations?

If there is any basic unit of biogeography, it is the geographic range of species; the shapes of ranges and the dynamic changes in their boundaries reflect the interacting influences of limiting environmental conditions (niche variables), dispersal and extinction dynamics, and historic effects (Brown et al. 1996; Gaston 2003). Thus, the present-day geographic information on species is able to reflect the environmental variation in nature and species data summarizes not only the entire spectrum of environmental conditions (perhaps unaccounted-for by the observer eyesight), but also the historic and demographic effects that produce dissimilar species assemblages in similar environments (Hortal and Lobo 2005). Having said this, the lack of knowledge of the geographic distribution of organisms, their interactions, and their role in natural processes is the major obstacle to develop reliable strategies of biodiversity conservation. Environment data, useful in the absence of detailed species data, should be used in conjunction with any newly-obtained species information, and the recording of taxonomic and distribution information should be

\footnotetext{
${ }^{1}$ http://europa.eu.int/comm/environment/nature/home.htm.
} 


\section{HORTAL AND LOBO - SYNECOLOGICAL CONSERVATION FRAMEWORK}

encouraged. Rather than considering only a limited number of organisms, or a limited, exclusive, environment database, as many species as possible, acceptably distributed throughout the evolutionary tree, should be taken into account. The exclusive use of distribution data is not advocated herein, but rather a framework based on biodiversity variables as conservation targets, that might reduce the need for environment surrogates, a complement to biodiversity distribution data. Should the latter be lacking, the former would become a target.

Conservation priority selection based on information available on known taxa would at least guarantee their protection as conservation targets in their own right (Brooks et al. 2004b). As detailed distribution and abundance data for most species in many regions is lacking (Andelman and Fagan 2000), former conservation approaches targeted just one or a few species (flagship, endangered, umbrella, and/or indicator species), assuming that regional biodiversity will be preserved by protecting these species and their habitats. However, this approach does not guarantee the protection of sites that encompass all regional biodiversity (see Simberloff 1998; Andelman and Fagan 2000; Williams et al. 2000; Possingham et al. 2002; Saetersdal et al. 2005), and can result in taking incomplete and/or erroneous decisions, so is currently abandoned.

To avoid oversimplification of describing biodiversity through the distribution of a reduced number of species, as much species' distribution information as possible should be compiled. The more detailed the information (both on spatial location and habitat description), the more useful for the monitoring and conservation of regional biodiversity (Austin 1998). Many initiatives are now devoted to gather extensive distribution data of organisms (among other information; see Edwards et al. 2000; Graham et al. 2004), making large amounts of information on a growing number of species and higher taxa available. The compilation of all the information on species now disseminated in the literature and Natural History collections will make an enormous source of information available. Although the analysis of this data will surely involve a number of problems (see, e.g., Dennis et al. 1999; Dennis and Thomas 2000; Dennis and Shreeve 2003; Gu and Swihart 2004; Molnar et al. 2004; Higgins et al. 2004; Cowling et al. 2004; Pressey 2004; Seoane et al. 2005), it is the only available basis to describe the spatial distribution of species (Brooks et al. 2004b). Interestingly, Gaston and Rodrigues (2003) show that even data gathered with relatively poor sampling effort can be highly effective for species representation.

However, as Higgins et al. (2004) point out, working in data-poor areas leads to the conclusion that such information is not sufficiently representative of biodiversity patterns. There are two shortfalls associated with the use of biological data for conservation biogeography (see Whittaker et al. 2005). First, our knowledge of global biodiversity, the conservation target, is fragmentary and taxonomically and geographically biased (the Linnean shortfall; Brown and Lomolino 1998). Second, adequate distribution data for many of the known species and higher taxa is lacking (the Wallacean shortfall; Lomolino 2004), and prone to taxonomic and geographic bias. These shortfalls could partially be compensated by selecting as many species as possible from those well-distributed in the tree of life, and by forecasting species distributions with methodologies capable of coping with incomplete data. Then, forecasted distributions could be used either for complementarity analyses (the autoecological approach) or to calculate biodiversity indices (a mixed autoecological-synecological approach) (see below). 


\section{HORTAL AND LOBO - SYNECOLOGICAL CONSERVATION FRAMEWORK}

Obtaining reliable data for regional conservation assessment

One of Systematic Conservation Planning's main objectives is to identify a set of representative areas (Dasmann 1972; Mackey et al. 1988; Belbin 1993; Church et al. 1996; Vane-Wright 1996; Powell et al. 2000), in which all species may persist if included in a reserve network (Araújo and Williams 2000; Araújo et al. 2004b). This is a key objective of several international conservation policy schemes, such as IUCN (MacKinnon and MacKinnon 1986a,b, MacKinnon et al. 1986) or WWF (Dinerstein et al. 1995; Olson and Dinerstein 1998) frameworks.

To develop processes for the selection and improvement of protected areas, objectives need to be specified (Margules and Pressey 2000). Along this line, much attention has been directed to algorithms based on complementarity, a measure of the biodiversity attributes found in newly-selected areas that would be added to those in a pre-existing network (Vane-Wright et al. 1991; Faith 1994; see also Hingston 1932). Complementarity was initially applied since the late 1980's, using presence-absence data to select areas for protection with one or more presences of as many species of a given group as possible (Margules et al. 1988; Pressey et al. 1993; Williams and Humphries 1994; Vane-Wright 1996). Other approaches have explored the power of composite variables to represent assemblage composition variability (e.g., Ferrier 2002; Ferrier et al. 2002b; Araújo et al. 2004a); or that of mixed datasets including environment variables, distribution information and predicted species distributions (e.g., Lombard et al. 2003; Cowling et al. 2003b; Sarkar et al. 2005). The three of them are enhanced by distribution information in biological databases, as well as by the latest methodologies now available (Church et al. 1996; Williams 1999; Cabeza and Moilanen 2001; Rodrigues and Gaston 2002), up-to-date but even so still having difficulties with complex conservation targets and datasets.

Therefore, in addition to using environmental surrogate data (see above), reserve selection procedures have also been developed from:

i) single species distribution data (an attempt to represent all species found in the region; e.g. Dobson et al. 1997; van Jaarsveld et al. 1998; Howard et al. 1998; Araújo 1999; Araújo and Williams 2000; Andriamampianina et al. 2000; Polasky et al. 2000; Martín-Piera 2001; Raxworthy et al. 2003);

ii) composite synecological attributes of biodiversity (aimed at protecting sites of great richness, rarity or endemism, or representing as much variability in community composition as possible), an approach less-used for conservation purposes (but see Margules et al. 1987; Bojórquez-Tapia et al. 1996; Iverson and Prasad 1998a,b; Zimmermann and Kienast 1999; Ferrier et al. 2002b; Gladstone 2002 or Araújo et al. 2004a).

The effectiveness of these selection algorithms depends on the accuracy of the input data. Therefore, biases in the geographical and/or ecological space covered by distribution information obtained from nonsystematic sampling may in turn bias descriptions of species geographic ranges and lead to major errors in the distribution of endangered or target species (Dennis 2001). This is probably a consequence of present Atlas data on the spatial distribution of species and biodiversity measures being far from accurate (van Jaarsveld et al. 1998; Dennis et al. 1999; Dennis and Thomas 2000), one of the most important weaknesses in current planning techniques for conservation area selection. Unavoidably, data obtained from sampling a given region constitutes just a group of samples, not a complete inventory (Nicholls and Margules 1993), and further sampling is needed to improve its quality, which usually 
would involve high costs, both in time and money (Prendergast et al. 1999). Atlases developed from additional sampling may yield diversity measures that vary greatly on broader scales and extents, while old and newly observed scores may not correlate (e.g. European butterflies: Dennis 1997; Dennis and Shreeve 2003). Thus estimates of synecological variables from well-sampled areas (e.g., Colwell and Coddington 1994 for species richness, or Chao et al. 2005 for compositional differences) would be of pragmatic value (see discussion below).

Modelling techniques can reduce the costs mentioned above by the extrapolation of biodiversity data to unexplored or poorlysampled areas, through the use of available environmental information with several methodologies of bioclimatic and geostatistic modelling (Nicholls 1989; Austin 1998; Ferrier 2002; Ferrier et al. 2002a,b; Lehmann et al. 2002a). For example, as Atlas data has improved, many predictions developed from old Atlases agree with the data presented in new ones (Dennis and Shreeve 2003). Biodiversity is now modelled mainly from: i) single species distribution data, one-by-one (autoecology, see Guisan and Zimmermann 2000; Scott et al. 2002; Ferrier et al. 2002a; Pearson and Dawson 2003; Peterson et al. 2004; Soberón and Peterson 2005; Araújo and Guisan 2006); or ii) composite biodiversity variables, such as species richness, assemblage composition, endemism, rarity, and others, assumed to be biodiversity surrogates for monophyletic groups (synecology; see Lobo and Martín-Piera 2002; Hortal et al. 2001, 2003, 2004; Ferrier 2002; Ferrier et al. 2002b; Ferrier and Guisan 2006).

If spatial distribution ranges of a number of species are modelled one-by-one, the complementarity criteria can be used to select nature reserves from such predictions. Nowadays, single-species distribution modelling predictions are considered reliable indicators for area selection (see, e.g.,
Williams et al. 2000; Andriamampianina et al. 2000; Araújo and Williams 2000; Peterson et al. 2000; Polasky et al. 2000; Araújo et al. 2002a; Lehmann et al. 2002b; Cabeza et al. 2004). Synecology, on the other hand, used infrequently for area selection (but see, e.g., Araújo et al. 2004a), has commonly been used just to identify biodiversity hotspots. However, several of these synecological variables (especially those describing community composition), may be of great utility for conservation (Ferrier 2002; Ferrier et al. 2002b). Whilst autoecology has received more attention and support, modelling synecological variables can be advantageous for area selection.

\section{THE ADVANTAGES OF THE SYNECOLOGICAL APPROACH}

In practical terms, compensating for data bias and model unreliability could be easier with the use of synecological variables because: i) the geographic clustering of prediction errors derived from autoecology models is eliminated; ii) it allows using data on the distribution of rare species (which under normal conditions can not be modelled due to paucity of records and/or presence sites); iii) reliable estimates of synecological variables for a group or a few groups of species involve fewer operations than estimates for all species one-by-one, including rare ones, thus reducing the effort involved in putting together a valid conservation proposal. Given the current state of ecological knowledge, there are also several theoretical advantages to the use of synecological variables: iv) they may reflect emergent assemblage properties not contained in the species level, but important to area selection, or even to the preservation of the characteristics of biodiversity phenomenon $\mathrm{per}$ $s e$; v) whilst species distribution ranges are expected to shift in response to climate change, many biodiversity surrogates may be stable over time. Of course details matter, but we should concentrate on why and where the 
woods are, before worrying about individual trees (Lawton 1999).

\section{Practical advantages}

1. Errors in the predictions of species' distributions

As mentioned above, a few studies have explored the usefulness of predicted species distribution one-by-one for complementarity analysis. However, these interpolations present many problems (see $\mathrm{Gu}$ and Swihart 2004) that could accumulate in predictions for a large group of species. Importantly, differing methodologies, extent, resolution, and/or kinds of distributions may produce varying estimates.

The performance of distribution prediction methods varies according to the geographic distribution, the equilibrium or not-equilibrium with the environmental conditions, the environmental requirements and natural history of the studied species (Guisan and Theurillat 2000; Guisan and Zimmermann 2000; Austin 2002; Pearson and Dawson 2003; Segurado and Araújo 2004; Brotons et al. 2004; Guisan and Thuiller 2005; Araújo et al. 2005a; Seoane et al. 2005; Soberón and Peterson 2005). Therefore, the choice of method should depend on the goals and kinds of distributions being modelled (Segurado and Araújo 2004; Soberón and Peterson 2005). Whilst one group of predictive methods try to model present-day spatial probabilities of occurrence (environmental conditions occupied by the species), others estimate habitat suitability for each species (potentially suitable environmental conditions; see Peterson et al. 1999). In single-species conservation planning, the latter are also useful for monitoring and re-introduction tasks (see Hirzel 2001; Hirzel et al. 2001, 2002, 2004; Chefaoui et al. 2005; Cassinello et al. in press). Lehmann et al. (2002a) favored the use of niche-based models for conservation purposes, but theoretical models may not work in real scenarios. For example, the range size of one third of the species used by Peterson et al. (2000) was overestimated by models based on realized niche. That is to say, models developed for single species failing to determine species absence from some territorial units with adequate environments.

Although theory and practice of predictive modelling is being continuously updated, drawbacks in data and in the theoretical assumptions under modelling techniques and predictors might cause the spatial accumulation of errors. The continuous development of tools and protocols is yet improving the power (and success) of modelling techniques (e.g., Scott et al. 2002; Anderson et al. 2003; Elith et al. 2006), although no single modelling strategy outperforms the rest in all occasions. Nevertheless, the ecological knowledge on the modelled species and the statistical skills of modellers might be more important than the method used for the correct prediction of species distributions (see Austin et al. 2006). Having said this, it is also known that errors in the predictor variables and/or, biases in observed species data and model inabilities to account for true distributions can produce a systematic bias (Flather et al. 1997; Fielding 2002). For example, most times data on the distribution of a species is biased to the center (either geographic or environmental) of its distribution (see Martínez-Meyer 2005). In addition, in some regions some parts of the geographic and environmental spaces have been repeatedly sampled through time, whereas others remained poorly known, being regional conditions underrepresented in the data at hand (Cabrero-Sañudo and Lobo 2003; J. Hortal, A. Jiménez-Valverde, J. F. Gómez, J. M. Lobo and A. Baselga, unpublished results; see discussion in Hortal and Lobo 2005).

Recent work on the theoretical assumptions under environmental niche modelling (e.g., Soberón and Peterson 2005; Araújo and Guisan 2006; Austin 2006) and the 
implementation of such theoretical advances in modelling techniques will result in an improvement of the accuracy of predictions in the future. However, the systematic character of the biases in biological data can result in a spatial aggregation of model errors (see Thuiller et al. 2004a,b and discussion in Araújo et al. 2005a,b and Soberón and Peterson 2005). Important evidence on such error accumulation was found by Araújo et al. (2005a); species richness patterns obtained from the sum of all individual model predictions for British birds correlated only slightly with observed patterns. According to Araújo and collaborators (2005a), aggregating predicted distributions for a number of species produces a propagation of false positives and negatives (model errors), which tend to concentrate at the edges of the observed distributions, as well as in some parts of the environmental spectrum. Thuiller et al. (2004a) found a similar pattern when modelling three tree species from environmental data restricted to their distribution ranges.

We hypothesize that the areas where errors could potentially accumulate would coincide with: i) range margins, where species usually suffer more stress (Brown 1984; see Loiselle et al. 2003; Araújo et al. 2005a); or ii) areas where community-level and/or historic processes, hard to model even for a single species, have played an important role in modifying species distributions (Woodward and Beerling 1997; Davis et al. 1998a,b; Pearson and Dawson 2003; see also Hampe 2004; Iverson et al. 2004; Skov and Svenning 2004; Thomas et al. 2004; Soberón and Peterson 2005 and Martínez-Meyer 2005). Therefore, most times species distributions are not in equilibrium with current climate conditions (see, e.g., Araújo and Pearson 2005), one of the basic assumptions of ecological niche modelling.

Prediction errors may come from either the model procedure or predictors used $(\mathrm{Gu}$ and
Swihart 2004), or biased or fragmentary biological data (Dennis et al. 1999; Dennis and Thomas 2000), apart from inadequacies in their theoretical assumptions. Atlas data usually does not include real absences (see Araújo and Williams 2000; Brotons et al. 2004; Soberón and Peterson 2005), where a given species has not been found despite exhaustive sampling. Many prediction methods require absence information, so their use implies the assumed absence of a species from a given set of sites. Although some promising alternatives exist which tries to identify absence points (Engler et al. 2004; Iverson et al. 2004; Lobo et al. 2006), model parameter estimates in such cases are generally affected by the bias in such 'added' data (false positives), even if sites are selected at random to avoid spatial or environmental bias (see $\mathrm{Gu}$ and Swihart 2004). Other procedures, such as ENFA (Ecological Niche Factor Analysis, see Hirzel et al. 2001), develop models of predicted species distribution using only presence data. Although this approach gives a picture on the suitable area occupied by the species, it presents the drawback that the location of suitable conditions is not the only factor influencing species distribution. Information on ecological and contingent constraints contained in, at least, a part of the absences, could be even more important for predicting species distribution range (see Lobo et al. 2006). Ignoring such information while modelling habitat suitability should probably produce less accurate predictions.

Model prediction errors are thus greater at environment and spatial range margins, and in the areas where historic processes have modified purely ecological distribution patterns, while reliable biological data is commonly biased towards well-sampled areas and common species. Due to such biases, it is likely that model errors should not be located randomly in space, but should form a pattern, as they are the result of phenomena with a defined spatial distribution that effect the 
distribution of each species differently. A recent work from Fortin et al. (2005) needs a complex set of methods to identify reliable species range margins for a single species, an unaffordable task to be applied to a great number of species in conservation studies. Thus, we hypothesize that complementarity analysis of a great number of predicted distributions together should involve the assumption that such errors will probably accumulate in space (see Flather et al. 1997 and Fielding 2002), having been summed repeatedly, and will give rise to major gaps in the biodiversity predicted for the selected areas. Further work would be necessary to confirm such a hypothesis outside the bounds marked by Thuiller et al. (2004a) and Araújo et al. (2005a and b).

\section{Rare or insufficient-data species}

Conservation planning based on species distribution predictions suffers from an inability to predict the distributions of many rare species, which may be underrepresented by complementarity selections when raw presence data from incomplete sampling effort is used (see Gaston and Rodrigues 2003). Data on these species is usually insufficient for the development of a good model (Peterson et al. 2000; Stockwell and Peterson 2002; Lehmann et al. 2002b; Gu and Swihart 2004; Hortal et al. 2005). When rare species are excluded, both areas selected by complementarity and rarity hotspots correlate poorly with those selected using information for all species (Araújo et al. 2005a). Thus, species-by-species predictions can exclude those rare species (Lobo and Hortal 2003), most of them critically endangered (Peterson et al. 2000), which, in general, are responsible for a great proportion of total diversity (Gaston 1994). For example, in the Iberian Peninsula, of the 21 insect species protected by the European Habitats directive, eleven have been recorded in fewer than ten $10 \times 10 \mathrm{~km}$ UTM grid squares, and five species in 4 or fewer squares
(Galante and Verdú 2000). To get around this problem, area selection should be based on both the predicted distribution of species that can be modelled and observed distributions for those species that can not (see, e.g., Lombard et al. 2003; Pressey 2004). However, this approach may underestimate both the distribution of geographically rare species, and of demographically rare (i. e., with small local abundance) but widely-distributed species (see Loiselle et al. 2003), which may be more difficult to record throughout all their distribution range (but see Gaston and Rodrigues 2003).

Rare species, of great interest for conservation purposes, are more sensitive to human disturbance, store a multitude of potentially useful adaptations, and also are responsible for the replacement of inventories among assemblages ( $\beta$-diversity). Assemblage distribution limits within a given territory (i. e., boundaries between presence and absence of representative species) are not usually well defined, but rather diffuse, with the number of species belonging to an assemblage changing gradually. To protect all biodiversity in a given territory, account must be taken of areas where this community replacement occurs (Ferrier 2002; Spector 2002), where many rare species could persist while populations of their competitors shrink, and where species belonging to the various assemblages in the region can co-occur. The exclusion of rare species data from the analyses may reduce the chances of identifying such replacement areas, especially in cases where, due to other factors, species replacement has not led to high values of species richness, regardless of the rarity of species present.

3. Estimates and predictions of synecological variables

Predictive maps of synecological variables can be obtained in three ways (Ferrier and Guisan 2006): (i) assemble first, predict later (i.e., aggregate species data into biodiversity 


\section{HORTAL AND LOBO - SYNECOLOGICAL CONSERVATION FRAMEWORK}

variables first, and then model these variables); (ii) predict first, assemble later (i.e., predict the distributions of species one-by-one and then aggregate these predictions into biodiversity variables); and (iii) assemble and predict together (i.e., use a joint procedure to establish relationships between species and predict their distribution using not only their environmental requirements, but also their patterns of co-occurrence). Although the third strategy presents the attractive characteristic of potentially taking into account biological interactions, we believe that the systematic bias in model errors and the lack of representation of rare species discussed above (sections 3.1.1 and 3.1.2) would result in a misrepresentation of these interactions, and therefore in bad-quality predictions. In the same way, we also believe that the 'first predicting and then assembling' strategy would result in erroneous pictures of the distribution of biodiversity due to the effect of these two topics, underperforming the results obtained by assembling first, and then predicting. On the contrary, we hypothesize that both the aggregation of errors and the lack of representation of rare species can be overcome by using the first strategy (assemble first, predict later) if two steps are previously added to the modelling protocol: a sampling effort assessment to identify the well-sampledenough areas (and discard those with unreliable inventories), and the extrapolation (when possible) of the scores of the synecological variables to diminish the effects of incomplete inventories (i.e., checklists are unlikely to be complete even at well-sampled areas) in these areas (see Hortal et al. 2004).

Modelling synecological variables, such as species richness, endemism, rarity, composition, and so on reduces the number of possible prediction errors to one per variable (instead of one per species). As these variables are based on data from many species in each territory unit, sampling effort assessment is easier. Species accumulation curves (Soberón and Llorente 1993; Colwell and Coddington 1994) can help to identify well-sampled areas for a given group of species (Lobo and MartínPiera 2002; Hortal et al. 2001, 2004; MartínPiera and Lobo 2003; Jiménez-Valverde and Hortal 2003). They can also yield estimates of richness scores for each territory unit, from information restricted to that unit (in addition to the many other species richness estimators available; see, e.g., Soberón and Llorente 1993; Colwell and Coddington 1994; Chazdon et al. 1998; Gotelli and Colwell 2001; Chiarucci et al. 2003; Brose et al. 2003). The results from several of these estimators could be comparable even when the biological information comes from heterogeneous sources (Hortal et al. 2006).

It should be pointed out that species richness alone is not the unique conservation target, but has to be integrated into a framework including other targets, such as rarity, endemism and, more importantly, complementarity. Recently, the development of non-parametric estimators for Jaccard and Sørensen indices (Chao et al. 2005), allows to avoid the erroneous estimates of compositional similarity between areas obtained from incomplete surveys, providing reliable complementarity measures from incomplete data. Errors in scores from present inventories are thus reduced by using estimates for each synecological variable, usually allowing the inclusion of a larger number of territorial units from a given area while enlarging the spatial and environmental coverage of observations. Reliability of models, built from more complete and robust data, is improved too. Interestingly, there is a reduction, or even elimination, of sampling bias in scores from models developed from asymptoticallyestimated richness values (see Hortal et al. 2004). Moreover, the set of species considered is enlarged by the inclusion of rare species in the estimates of biodiversity surrogate scores, which become a major part of final values. Rarity itself can be also estimated for each 
territorial unit (see Gaston 1994), as can other surrogates, such as $\beta$-diversity (Faith and Ferrier 2002; Ferrier 2002; Ferrier et al. 2002b), endemism (Lumaret and Lobo 1996), assemblage composition (Ferrier 2002; Hortal et al. 2003; Araújo et al. 2004a; Ferrier and Guisan 2006).

Appropriate sampling effort assessment along with surveys designed to cover all spatial variations of biodiversity (see Hortal and Lobo 2005) could even make data from more taxonomic groups available, with a minor investment of finance and time. Here, it is important to notice that several groups and higher taxa could serve as surrogates of other groups, for either local species richness (Balmford et al. 2000; Cardoso et al. 2004a,b), and geographic variations (MacNally and Fleishman 2004; Fleishman et al. 2005; Thomson et al. 2005; Tognelli 2005; Tognelli et al. 2005; Larsen and Rahbek 2005). Therefore, a limited group of taxa could give a good picture of overall biodiversity variation, although their surrogacy presents several limitations (see, e.g., Thomson et al. 2005; Tognelli et al. 2005).

Prediction errors in the estimates may also be reduced through the use of available geostatistic methodologies (Carroll and Pearson 2000; Ter Steege et al. 2003), which model variables using spatial location as predictor (alone or together with environment variables, e.g. Tognelli and Kelt 2004). Homogeneous estimates, such as the asymptotic species richness described above, can reduce the extreme sensitivity of these methodologies to input data error. Also, the use of spatial location as predictor may allow the effect of unknown or unaccounted-for effects and/or historic processes (see, e.g., Mac Nally et al. 2003) to be included in environment-based models, and so improve the power and accuracy of estimates (see Lobo and Martín-Piera 2002; Hortal et al. 2001; Lobo et al. 2001, 2002).

\section{Theoretical advantages}

The three practical advantages discussed above indicate that biodiversity can readily be described by synecological variables. Evidently, a theoretical advantage of using these variables to describe the geographic variations of a group of organisms that share a common evolutionary past is that the patterns in these compound variables arise from the response of their common adaptations and divergences to conditions in the territory studied. However, the most important benefit to conservation may come from the agreement of synecology with current developments in theoretical ecology. Current evidence for chaotic structure in ecological systems suggests that the interrelationships among their components (species and individuals) may play a key role in ecosystem functioning. The complex interactions among these components would be the cause of the properties and dynamics of such systems (see, e.g., Brown et al. 2002; Bolliger et al. 2003; or Gorshkov et al. 2004). Therefore, these emergent properties pertain neither to individuals nor species, but to the whole of ecosystem biodiversity.

We are going to focus on two different topics. Recent theoretical advances indicate that biodiversity as a phenomenon may affect ecosystem functions such as productivity and resilience (e.g., species richness and composition; see Tilman et al. 1996; Yachi and Loreau 1999; Tilman 2000, 2001; Kennedy et al. 2002; Bond and Chase 2002; Loreau et al. 2003). Moreover, in some places assemblages of several groups were stable through time (see Brown et al. 2001; or Fleishman and Mac Nally 2003); even through the dramatic Holocene climate changes (see Rodríguez 2004). In this context, ecosystem resilience has been related to diversity (Tilman et al. 2006), providing a link between diversity, enhanced ecosystem functioning and community resistance (and thus stability) against environmental changes. Other biodiversity aspects, such as assemblage 
replacement, may remain invariant due to the particular geomorphology of a region (see Spector 2002), or to the resilience of the system.

\section{Detection of evolutionarily important areas}

Species populations go under ecophysiological stress (see Hengeveld 1990) and are more threatened (Araújo and Williams 2000) in range margin areas. There, environmental conditions are more rigorous than in core areas, and populations become isolated easily at range margins. Therefore, evolutionary processes could be enhanced due to ecophysiological stress (i.e., species adaptations are often pushed to the limit; Brown 1984; Brussard 1984; Case et al. 2005) and the genetic differentiation caused by isolation. In addition, it is known that environmental stress increases retrotransposon activity (see Sentís 2002), favoring symbiotic interactions (e.g., Russell et al. 2003), and promoting lateral gene transmission (see Nieto et al. 2004). In addition, many species may survive human disturbance or climate change in a given region (threatened or at range-margins) by adapting new life-history strategies, such as the modification of their micro-distributions and/or near environment (e.g. insects; Danks 2002). Therefore, it can be expected that some evolutionary processes may take place in these peripheral areas (see, e.g., Thomas et al. 2001).

Given that evolutionary processes occur throughout space as well as over time, if conservation policies miss the areas where changes, re-sampling and additions to the evolutionary pool of the biota they intend to preserve are occurring, they might not conserve information and processes vital to nature's resilience. Policies based on single species distribution data may so fail to represent such phenomena, but those based on synecological variables may take them into account. Their fewer dimensions summarize a greater proportion of the total variability attributable to all the species in a given territory, and should better represent the various facets of regional biodiversity. In this context, the environmental or geographic conditions limiting species distributions in their range margins often result in zones of ecological transition, where species replacement ( $\beta$-diversity) and richness scores are high due to the joint appearance of different assemblages. Therefore, we hypothesize that some areas of evolutionary importance could be identified by some combinations of these synecological variables. However, the importance of range margins for conservation is still unknown, as the probabilities of species persistence are lower in peripheral than in core areas (see Araújo et al. 2002b).

\section{Community processes, emergent properties} and stability along environmental changes

Species distribution ranges have shifted throughout the Quaternary (see, e.g., Hewitt 1996, 1999; Bradshaw 1999) and the last century (Lewis and Bryant 2002; Walther et al. 2002). Such shifts are expected to continue due to human activity and climate change (see Midgley et al. 2003, Sparks et al. 2005). Many of these shifts are being identified nowadays in a number of groups such as butterflies (Parmesan et al. 1999; Warren et al. 2001; Hill et al. 2002), dung beetles (Lobo 2001), birds (Thomas and Lennon 1999; Walther et al. 2002) or dragonflies (Hickling et al. 2005). Such process gets even worse due the effects of land degradation by human impact (see Pyke and Fischer 2005). If these range shifts could be predicted with reliability, conservation policies could include both present and future distributions of biodiversity.

The reliability of the extrapolation of future species distributions by applying the predictive models based on current environmental conditions to future climate scenarios is currently a matter of debate. Although many recent works include the 


\section{HORTAL AND LOBO - SYNECOLOGICAL CONSERVATION FRAMEWORK}

implications of climate change on conservation planning (e.g. Peterson et al. 2002; Hannah et al. 2002; Araújo et al. 2004b; Pyke and Fischer 2005), it has been repeatedly argued that the current state of knowledge of species range shifts can not yet be used to produce reliable extrapolations of future distributions (see Pearson and Dawson 2003, 2004; Hampe 2004; Thuiller et al. 2004a; but see Araújo et al. 2004b, 2005b; Pyke and Fischer 2005). Certainly, there is evidence on the coincidence of the environmental responses of some species in their recent and past distributions due to niche conservatism (Martínez-Meyer et al. 2004; A.T.Peterson and E.Martínez-Meyer, unpublished results). Such evidence indicates that it would be possible to extrapolate current environmental responses to future climate scenarios. However, we do not know how general is niche conservatism, and evidence is also available on increased evolutionary rates under changing conditions (see section 3.2.1).

The accuracy of using current speciesenvironment relationships to estimate past climate conditions in Palaeontology is doubtful, as the factors affecting past and present species distributions may have varied (Rodríguez 1999; Rodríguez and Nieto 2003). By extension, present distribution response to present-day factors may differ from future distribution response to similar factors; thus, extrapolating future species distributions from their current relationship with climate might be problematic. In both cases, the role of historic (past and future) processes throughout time is unknown. Therefore, modelling based on inherently co-linear environmental variables can not identify causal predictor relationships with species distribution, so extrapolation to other climate scenarios may not be meaningful (Hampe 2004). Taking this into account, conservation networks based on current species distributions may not be effective (Margules et al. 1994; Prendergast et al. 1999), and may need to be updated in a few decades.
However, nature reserves are not yet selected and managed with an eye to the impact of climate change on species abundance and distribution (Lawton 1997). Short-term focused conservation will fail to protect on the long-term both biodiversity and the processes it generates and supports.

However, community stability in structure and richness over time has been reported for various regions, extents, time periods, and taxa, despite changes in composition (Brown et al. 2001; Sax 2002), human induced impacts, or strong climate changes, even during glacial periods (Rodríguez 2004). Current evidence indicates that some of the many processes modifying biodiversity spatial distribution may remain relatively constant regardless of environmental variations.

The relationship between productivity and richness has been extensively documented; the more productive the site, the larger the species richness (Tilman and Pacala 1993; Tilman et al. 1996, 1997a,b; Srivasta and Lawton 1998; Tilman 1999, 2000; Lehman and Tilman 2000). Such high diversity acts as a reservoir of evolutionary solutions, improving the efficiency of ecosystem functioning (and, thus, productivity) in the presence of environmental changes (insurance hypothesis; see Yachi and Loreau 1999; Loreau et al. 2003); systems with greater richness (or high species replacement, see below) may maintain productivity in spite of environmental change through the replacement of individuals of species in suboptimal conditions by those in optimum conditions (but see Emmerson et al. 2005). High productivity (i.e., enhanced ecosystem functioning) provides resilience to environmental changes (Tilman et al. 2006), and is also a key factor in maintaining the structure of ecological systems (Brown et al. 2001). In addition, species-rich local communities are able to resist the establishment and effects of invasive species (Levine and D'Antonio 1999; Burger et al. 2001; Kennedy et al. 2002), favoring temporal 
stability. Nevertheless, dependence on initial conditions, characteristic of complex systems, may also lead to long-term structural stability in an ecosystem, in the absence of glaciations or other major disturbances to the processes occurring in a given area (e.g., Quaternary mammal communities; Rodríguez 2006). After each major perturbation, a new assembly, and development of assemblages, may lead to structurally different systems, which may, in turn, be stable despite minor perturbations. Such inertia may be a synecological property of many systems or assemblages.

Shape, relief and location of a given site or region also affect the spatial distribution of biodiversity (Burnett et al. 1998; Nichols et al. 1998; Jetz and Rahbek 2001). Environmental heterogeneity is in part the result of geomorphology and bedrock geology, which remain relatively stable during long periods of time. As commented above, the great variety of habitats present at environmentally heterogeneous areas promote higher species richness and replacement. For similar causes, some of these areas may become corridors for population range shifts of many different species under climate change conditions due to their particular geomorphology (e.g., latitudinal mountain chains, see Lobo and Halffter 2000; or Spector 2002). These 'biogeographic crossroads' may also shelter high $\alpha$ and $\beta$-diversities, even while species composition change and populations fluctuate. Therefore, species richness and replacement may remain constant throughout time in some of the areas important for the migration of most species during their range shifts. In the same way, some factors that favor endemism, such as isolation, may also stay constant (e.g., islands; see Whittaker 1998; Borges and Brown 1999; Emerson 2002; Gillespie and Roderick 2002).

In sum, several biodiversity facets may remain constant throughout time, and could present resilience to human impact. Identifying the synecological variables that are the output of these facets, and basing regional conservation assessments on them may increase the probability of conserving more biodiversity, and of protecting areas vital to evolutionary processes.

SYNECOLOGICAL VARIABLES AS A BASIS FOR REGIONAL SYSTEMATIC CONSERVATION PLANNING

As Pimm and Lawton (1998) stated, species may not be the correct units to use complementarity as conservation criterion. Thus, other descriptors of geographic biodiversity variations must be found. As discussed above, the geographic range of species is neither invariant, nor easy to describe accurately. In most cases, observed single-species distribution is not reliable enough to be used in predictive modelling, and is even less so for complementarity-based selections. As we have shown, a pragmatic alternative could be the use of the synecological variables to describe the spatial distribution of biodiversity.

While it might be argued that these variables fail to contain useful information contained in single-species distributions, it is widely known that an appropriate spatial scale reduces the 'noise' present in these variables due to differences in the distributions of a large number of species (see, e.g., Brown et al. 2002; or Willis and Whittaker 2002). Community ecology is a mess, with so much contingency that useful generalizations are hard to find. There are not as many kinds of population dynamics as species on Earth, but a multitude of essentially trivial variations on a few common themes (Lawton 1999). Finding laws or patterns in nature's chaotic organization, where species and environment dynamics and interactions combine to produce fractal complexity over time (e.g., Brown et al. 2002; or Bolliger et al. 2003), involves a proper choice of scale, organization level and extent examined (Levin 1992; Lawton 1999; 


\section{HoRTAL AND LOBO - SYNECOLOGICAL CONSERVATION FRAMEWORK}

Brown et al. 2002; Willis and Whittaker 2002).

The biodiversity patterns described by synecological variables can be useful at virtually any grain size, as they provide information about processes at each level of resolution (Blackburn and Gaston 2002; Willis and Whittaker 2002). Due to the fractal nature of the processes under these patterns, several "windows of order" appear along scale change. There, auto-organization increases, and noise is reduced, producing sharper patterns. One or several of these windows are the subject of study of biogeography and macroecology (see Brown 1995; and Brown and Lomolino 1998). Grids of 10- to 100-km width $(0.1$ to 1 geographic degrees approximately), such as those used in most regional Systematic Conservation Planning assessments can reasonably be expected to resolve macroecology and biogeography patterns (depending on group studied and purpose of analysis). Predictions can be obtained for such composite variables as species richness ( $\alpha$-diversity), species turnover ( $\beta$-diversity), community composition, rarity, endemism, etc. (Ferrier 2002; Lobo and Hortal 2003), whose utility as descriptors of biodiversity is not open to discussion.

One of these variables alone is unlikely to adequately describe the distribution and function of the whole of biodiversity, since it is unlikely that all the facets of biodiversity could be summarized by a single index (see Gaston 1996). For example, both species number and composition have been related to ecosystem properties (see debate in Tilman et al. 1996, 1997a,b; and Wardle et al. 1997), and endemism may be related to the danger of extinction in an area (Pimm et al. 1995), or to the rate of taxonomic replacement between two assemblages. However, maps of predicted values of a small set of these variables may display the main spatial patterns of biodiversity in a given area, patterns that may differ substantially from the ones derived from the aggregation of single-species information. Even more, if these variables are the expression of several of the facets of biodiversity, it could be possible to find a reduced number of composite factors, namely 'biodiversity factors', that summarize all the different aspects covered by the related synecological variables that are today in use.

However, their use as predictors would require first: i) design of sampling strategies to obtain reliable information on spatial biodiversity patterns using a minimum set of sites representative of environmental and spatial variability (Austin 1998; Dennis and Hardy 1999; Ferrier 2002; Hortal and Lobo 2005; see also Araújo and Guisan 2006); ii) inclusion of a measure of sampling effort or, at least, a surrogate, in the databases used to gather information for distribution Atlases (Austin 1998; Dennis et al. 1999; Dennis and Thomas 2000); and iii) production of maps of as many predicted biodiversity components as possible, such as species richness, rarity, endemism or composition differences (Carroll and Pearson 1998a; Pearson and Carroll 1999; Hortal et al. 2001, 2003, 2004; Lobo and Martín-Piera 2002; Ferrier 2002; Ferrier et al. 2002b).

Traditionally, maps of biodiversity measures alone have not been used to depict all spatial variations in the assemblages of a given group, but only to identify hotspots and impoverished zones (see Balmford 1998 or Kitching 2000; and several examples at Prendergast et al. 1993; Gaston and David 1994; Heikkinen and Neuvonen 1997; Araújo 1999; Hortal et al. 2001, 2004; Martín-Piera 2001). This restricted use was partially amplified with the advent of complementarity, easier to apply directly to single-species distributions. Tools to apply the complementarity criterion to synecology descriptions of biodiversity now exist. Ferrier and collaborators (Ferrier 2002; Ferrier et al. 2002b) suggest using information on wellsurveyed sites to identify groups of sites with 
similar assemblages, or groups of species occurring at similar sites, to subsequently model and extrapolate these multinomial variables. They also propose a promising procedure, the use of generalized linear matrix regression, to model composition dissimilarities between all pairs of survey sites as a function of the distances in one or several explanatory matrices (Generalized Dissimilarity Modelling; GDM). The square matrix of the distances between well-surveyed localities can be used to build a triangular distance matrix that can be used in ordination procedures, to derive one or more continuous factors representing composition differences between localities. These scores can be modelled, as can any other continuous variable, and their values extrapolated to the unsampled territory (Hortal et al. 2003). Selecting localities representative of most of the variability represented in the matrix by modelling a number of synecological variables is a procedure similar to the one proposed by Faith and Walker (1996a; see also Araújo et al. 2004a). The performance of synecology procedures should be compared with that obtained currently by modelling individual species to select areas for conservation (e.g. Cabeza et al. 2004; Sánchez-Cordero et al. 2005). However, we believe that the synecology approach promises a theoretically robust use of biodiversity measures to decide where and how to locate protected areas.

Of course, the goodness-of-fit and utility of predicted synecology maps should increase with increasing scale (Carroll and Pearson 1998b; Pearson and Carroll 1999; Murguía and Villaseñor 2000), while the main patterns of variation may be obscured by small-scale processes at smaller spatial resolutions (see Prendergast et al. 1999). Nevertheless, using just biological data alone to locate protected areas is not practical, as the selected sites may not be adequate for reserve implementation, or the spatial resolution may be too small to provide areas able to host viable populations
(Pimm and Lawton 1998). Thus, regional conservation goals must be large-scale; then site networks should be designed in each important area on a smaller scale. In this step, downscaling techniques (see, e.g. Araújo et al. 2005a) can be used to obtain a sharper picture of biodiversity patterns and the distribution of target species (see, e.g., Barbosa et al. 2003). Much national and continental Atlas data can be referred to homogeneous territorial units, such as UTM grid cells (e.g., $50 \mathrm{~km}$ width), or even broad geographic grid units, such as the units of $0.5^{\circ}$, which have approximately the same surface area except at extreme north and south latitudes. For most regions, even smaller grid sizes, such as $10 \times 10$ - or $20 \times 20-\mathrm{km}$ grids may be used, but before doing so it is necessary to develop a general, wideresolution basis for conservation planning.

Since no group can be used alone as an indicator for all biodiversity, as many groups as possible are needed to cover all the kinds of spatial dynamics, of the few that may exist (Lawton 1999). As stated above, good Atlas data is available only for a few groups, mainly plants and vertebrates. Such Atlases are very difficult to obtain for the groups of species, such as invertebrates, that represent the greater portion of overall biodiversity (see, e.g., Wilson 2002). However, it is relatively easy to obtain good inventories of a number of these less well-known taxonomic groups from a limited number of localities or grid cells. If these sites are environmentally and spatially well-distributed (Hortal and Lobo 2005), such partial information can be used to obtain acceptable predictions of synecological biodiversity attributes.

Synecological variables, much more rapid to use, can produce more reliable estimates, and may also help to detect emergent properties of assemblages not contained in single-species distributions, nor thus even in cumulative single-species predictions. So a practical approach to the use of synecological variables for conservation assessment is 
needed. During the 80s and 90s, the sound work of Australian CSIRO and Conservation Agencies led to the development of regional, analytical and systematic territorial planning of biodiversity preservation. According to Margules and Pressey (2000), the six consecutive stages, including feedback from the last stages to improve the effectiveness of the previous ones, of this approach are: i) obtain regional biodiversity data, a stage consisting of compilation and evaluation of previously existing knowledge, sampling, and extrapolation (Austin 1998); ii) identify regional conservation goals; iii) assess the effectiveness of current reserve network; iv) select additional areas for protection (see Pressey and Nicholls 1989; Pressey et al. 1993, 1996; or Faith and Walker 1996a,b); v) implement conservation actions; and vi) maintain at appropriate levels in the protected areas the indicators that have been used as conservation goals. In the context of biological data scarceness described herein, we propose the use of the first four stages set out in Margules and Pressey 2000 (see also Austin 1998 and Ferrier 2002) with which to select areas effectively, from a synecological perspective, supported by currently available single-species data and environmental surrogacy to:

i) Obtain reliable data for as many groups as possible (see Hortal and Lobo 2005): (a) Compile and analyze existing information to identify areas with reliable inventories; (b) design and run a survey to optimize data on biodiversity patterns; and (c) reexamine that data.

ii) Select the biodiversity attributes to be used, and estimate their scores in those territorial units with well-established information. Gaps in distributional data should be filled in by selected environmental surrogates.

iii) Interpolate the scores of these biodiversity attributes to all regional territorial units by means of spatialenvironmental modelling.

iv) Analyze the effectiveness of current reserve network for biodiversity protection, and develop a proposal for new areas and structural elements (corridors and/or micro-reserves) to maximize this effectiveness, using both the complementarity criterion with species composition variables, and by selecting the areas with higher species richness, endemism, etc., according to the results of the research agenda proposed above. Additional data on species of interest should play a central role in Once the bulk of priority areas had been established using synecological variables, additional information on the distribution (either observed or predicted) of species of special interest (i.e., protected species or wellknown indicators) and on land types (descriptive of landscape composition) can be then added to area selection processes to improve the coverage of all conservation goals at stake, and to reserve design processes (part of Margules and Pressey v and vi stages) to be accounted for in the final spatial configuration of the reserve network.

These four steps are relatively easy to carry out for a single group with limited staff, time, and funds (for a complete example, see Hortal 2004). Thus, effective reserve networks could be designed in a short period, with a small investment, and be integrated into biodiversity monitoring such as that expounded on by Green et al. (2005). Some $a$ priori prioritization of synecological variables can be established from scratch, based on current theoretical knowledge on community ecology and assembly, and biodiversity and ecosystem functioning. For example, first use composition patterns to improve complementarity coverage, then try to cover functional diversity, and then select richest 


\section{HORTAL AND LOBO - SYNECOLOGICAL CONSERVATION FRAMEWORK}

areas within the selected to include more resilient/better functioning assemblages, then rarity and/or endemism, and so on (see some clues below). However, such decisions might rely on current prejudices/concepts on what to protect and how ecosystems are functioning, fields where some debate does exist (especially in the latter). Therefore, a research agenda is needed to determine how these variables are able to identify and/or cover i) areas of higher resilience, ii) some stability in the patterns of species composition or complementarity, or iii) species, communities or landscapes identified as conservation goals. Such research might necessarily involve the use of good quality real data taken at different periods of time to ensure that its conclusions could be taken as a baseline for conservation schemes.

\section{CONCLUSIONS}

We have summarized a number of practical and theoretical advantages of using a synecological approach in Systematic Conservation Planning. The conservation value of synecological variables is transparent and easy for policy makers to understand, as only a few variables are needed to design the core of a reserve selection. Therefore, the advantages of the synecology approach make its use advisable for current reserve selection procedures. Further studies would evaluate how this approach may be implemented most effectively (i.e., which biodiversity aspects should be prioritized and/or preferently used in complementarity approaches), to what extent the results obtained with selections based on other biodiversity surrogacy strategies are improved upon by the use of synecology, and, more importantly, to what extent propositions based on synecological variables provide resilient area networks able to face environmental changes through time.

\section{ACKNOWLEDGEMENTS}

The authors wish to thank Town Peterson, Richard Cowling and several anonymous referees for their comments and suggestions on former versions of this work, and to James Cerne for his exhaustive English review. This work was supported by the Spanish MEC project CGL2004-0439/BOS and the Fundación BBVA project "Yamana - Diseño de una red de reservas para la protección de la biodiversidad en América del Sur Austral utilizando modelos predictivos de distribución con taxones hiperdiversos". JH was also supported by a Portuguese FCT postdoctoral grant (BPD/20809/2004).

\section{LITERATURE CITED}

Airame, S., J. E. Dugan, K. D. Lafferty, H. Leslie, D. A. McArdle, and R. R. Warner. 2003. Applying ecological criteria to marine reserve design: A case study from the California Channel Islands. Ecological Applications 13:S170-S184.

Andelman, S. J., and W. F. Fagan. 2000. Umbrellas and flagships: Efficient conservation surrogates or expensive mistakes? Proceedings of the National Academy of Sciences of the USA 97:5954-5959.

Anderson, R. P., D. Lew, and A. T. Peterson. 2003. Evaluating predictive models of species' distributions: criteria for selecting optimal models. Ecological Modelling 162:211-232.

Andriamampianina, L., C. Kremen, D. Vane-Wright, D. Lees, and V. Razafimahatratra. 2000. Taxic richness patterns and conservation evaluation of Madagascan tiger beetles (Coleoptera: Cicindelidae). Journal of Insect Conservation 4:109-128.

Araújo, M. B. 1999. Distribution patterns of biodiversity and the design of a representative reserve network in Portugal. Diversity and Distributions 5:151-163.

Araújo, M. B., and P. H. Williams. 2000. Selecting areas for species persistence using occurrence data. Biological Conservation 96:331-345.

Araújo, M. B., and R. G. Pearson. 2005. Equilibrium of species' distributions with climate. Ecography 28:693-695.

Araújo, M. B., and A. Guisan. 2006. Five (or so) challenges for species distribution modelling. Journal of Biogeography 33:doi:10.1111/j.13652699.2006.01584.x.

Araújo, M. B., C. J. Humphries, P. J. Densham, R. Lampinen, W. J. M. Hagemeijer, A. J. Mitchell- 


\section{HORTAL AND LOBO - SYNECOLOGICAL CONSERVATION FRAMEWORK}

Jones, and J. P. Gasc. 2001. Would environmental diversity be a good surrogate for species diversity? Ecography 24:103-110.

Araújo, M. B., P. H. Williams, and A. Turner. 2002a. A sequential approach to minimise threats within selected conservation areas. Biodiversity and Conservation 11:1011-1024.

Araújo, M. B., P. H. Williams, and R. Fuller. 2002 b. Dynamics of extinction and the selection of nature reserves. Proceedings of the Royal Society of London B 269:1971-1980.

Araújo, M. B., P. J. Densham, and P. H. Williams. 2004a. Representing species in reserves from patterns of assemblage diversity. Journal of Biogeography 31:1037-1050.

Araújo, M. B., M. Cabeza, W. Thuiller, L. Hannah, and P. H. Williams. 2004b. Would climate change drive species out of reserves? An assessment of existing reserve-selection methods. Global Change Biology 10:1618-1626.

Araújo, M. B., W. Thuiller, P. H. Williams, and I. Reginster. 2005a. Downscaling European species atlas distributions to a finer resolution: implications for conservation planning. Global Ecology and Biogeography 14:17-30.

Araújo, M. B., R. J. Whittaker, R. J. Ladle, and M. Erhard. 2005b. Reducing uncertainty in projections of extinction risk from climate change. Global Ecology and Biogeography 14:529-538.

Austin, M. P. 1998. An ecological perspective on biodiversity investigations: examples from Australian eucalypt forests. Annals of the Missouri Botanical Garden 85:2-17.

Austin, M. P. 2002. Spatial prediction of species distribution: an interface between ecological theory and statistical modelling. Ecological Modelling 157:101-118.

Austin, M. 2006. Species distribution models and ecological theory: A critical assessment and some possible new approaches. Ecological Modelling in press:doi:10.1016/j.ecolmodel.2006.1007.1005.

Austin, M. P., L. Belbin, J. A. Meyers, M. D. Doherty, and M. Luoto. 2006. Evaluation of statistical models used for predicting plant species distributions: Role of artificial data and theory. Ecological Modelling press:doi:10.1016/j.ecolmodel.2006.1005.1023.

Balmford, A. 1998. On hotspots and the use of indicators for reserve selection. Trends in Ecology and Evolution 13:409.

Balmford, A., A. J. E. Lyon, and R. M. Lang. 2000. Testing the higher-taxon approach to conservation planning in a megadiverse group: the macrofungi. Biological Conservation 93:209-217.

Barbosa, A. M., R. Real, J. Olivero, and J. M. Vargas. 2003. Otter (Lutra lutra) distribution modelling at two resolution scales suited to conservation planning in the Iberian Peninsula. Biological Conservation 114:377-387.

Belbin, L. 1993. Environmental representativeness: regional partitioning and reserve selection. Biological Conservation 66:223-230.

Blackburn, T. M., and K. J. Gaston. 2002. Scale in macroecology. Global Ecology and Biogeography 11:185-189.

Bolliger, J., J. C. Sprott, and D. J. Mladenoff. 2003. Self-organization and complexity in historical landscape patterns. Oikos 100:541-553.

Bond, E. M., and J. M. Chase. 2002. Biodiversity and ecosystem functioning at local and regional spatial scales. Ecology Letters 5:467-470.

Bojórquez-Tapia, L. A., I. Azuara, E. Escurra, and O. Flores-Villela. 1996. Identifying conservation priorities in México through geographic information systems and modelling. Ecological Applications 5:215-231.

Borges, P. A. V., and V. K. Brown. 1999. Effect of island geological age on the arthropod species richness of Azorean pastures. Biological Journal of the Linnean Society 66:373-410.

Bradshaw, R. H. W. 1999. Spatial responses of animals due to climate change during the Quaternary. Ecological Bulletins 47:16-21.

Brooks, T., G. A. B. da Fonseca, and A. S. L. Rodrigues. 2004a. Protected areas and species. Conservation Biology 18:616-618.

Brooks, T., G. A. B. da Fonseca, and A. S. L. Rodrigues. 2004b. Species, data, and conservation planning. Conservation Biology 18:1682-1688.

Brose, U., N. D. Martinez, and R. J. Williams. 2003. Estimating species richness: Sensitivity to sample coverage and insensitivity to spatial patterns. Ecology 84:2364-2377.

Brotons, L., W. Thuiller, M. B. Araújo, and A. H. Hirzel. 2004. Presence-absence versus presenceonly based habitat suitability models for bird atlas data: the role of species ecology and prevalence. Ecography 27:285-298.

Brown, J. H. 1984. On the relationship between abundance and distribution of species. American Naturalist 124:255-279.

Brown, J. H. 1995. Macroecology. University of Chicago Press, Chicago.

Brown, J. H., and M. V. Lomolino 1998. Biogeography. Second edition. Sinauer Associates, Inc., Sunderland, Massachussets.

Brown, J. H., G. C. Stevens, and D. M. Kaufman. 1996. The geographic range: Size, shape, boundaries, and internal structure. Annual Review of Ecology and Systematics 27:597-623.

Brown, J. H., S. K. M. Ernest, J. M. Parody, and J. P. Haskell. 2001. Regulation of diversity: maintenance 


\section{HORTAL AND LOBO - SYNECOLOGICAL CONSERVATION FRAMEWORK}

of species richness in changing environments. Oecologia 126:321-332.

Brown, J. H., V. K. Gupta, B.-L. Li, B. T. Milne, C. Restrepo, and G. B. West. 2002. The fractal nature of nature: power laws, ecological complexity and biodiversity. Philosophical Transactions of the Royal Society of London B 357:619-626.

Brussard, P. F. 1984. Geographic patterns and environmental gradients: the central-marginal model in Drosophila revisited. Annual Review of Ecology and Systematics 15:25-64.

Burger, J. C., M. A. Patten, T. R. Prentice, and R. A. Redak. 2001. Evidence for spider community resilience to invasion by non-native spiders. Biological Conservation 98:241-249.

Burnett, M. R., P. V. August, J. H. Brown Jr., and K. T. Killingbeck. 1998. The influence of geomorphological heterogeneity on biodiversity. I. A patch-scale perspective. Conservation Biology 12:363-370.

Cabeza, M., and A. Moilanen. 2001. Design of reserve networks and the persistence of biodiversity. Trends in Ecology and Evolution 16:242-248.

Cabeza, M., M. B. Araújo, R. J. Wilson, C. D. Thomas, M. J. R. Cowley, and A. Moilanen. 2004. Combining probabilities of occurrence with spatial reserve design. Journal of Applied Ecology 41:252262.

Cabrero-Sañudo, F. J., and J. M. Lobo. 2003. Estimating the number of species not yet described and their charactersitics: the case of Western Palaearctic dung beetle species (Coleoptera, Scarabaeoidea). Biodiversity and Conservation 12:147-166.

Cardoso, P., I. Silva, N. G. de Oliveira, and A. R. M. Serrano. 2004a. Higher taxa surrogates of spider (Araneae) diversity and their efficiency in conservation. Biological Conservation 117:453459.

Cardoso, P., I. Silva, N. G. de Oliveira, and A. R. M. Serrano. 2004b. Indicator taxa of spider (Araneae) diversity and their efficiency in conservation. Biological Conservation 120:517-524.

Carroll, S. S., and D. L. Pearson. 1998a. Spatial modeling of butterfly species diversity using tiger beetles as a bioindicator taxon. Ecological Applications 8:531-543.

Carroll, S. S., and D. L. Pearson. 1998b. The effects of scale and sample size on the accuracy of spatial predictions of tiger beetle (Cicindelidae) species richness. Ecography 21:401-414.

Carroll, S. S., and D. L. Pearson. 2000. Detecting and modeling spatial and temporal dependence in conservation biology. Conservation Biology 14:1893-1897.

Case, T. J., R. D. Holt, M. A. McPeek, and T. H. Keitt. 2005. The community context of species' borders: ecological and evolutionary perspectives. Oikos 108:28-46.

Cassinello, J., P. Acevedo, and J. Hortal. in press. Prospects for population expansion of the exotic aoudad (Ammotragus lervia; Bovidae) in the Iberian Peninsula: clues from habitat suitability modelling. Diversity and Distributions.

Chao, A., R. L. Chazdon, R. K. Colwell, and T.-J. Shen. 2005. A new statistical approach for assessing similarity of species composition with incidence and abundance data. Ecology Letters 8:148-159.

Chazdon, R. L., R. K. Colwell, J. S. Denslow, and M. R. Guariguata. 1998. Statistical methods for estimating species richness of woody regeneration in primary and secondary rain forests of NE Costa Rica. Pp. 285-309 in F. Dallmeier, and J. A. Comiskey, eds. Forest biodiversity research, monitoring and modeling: Conceptual background and Old World case studies. Parthenon Publishing, Paris.

Chefaoui, R. M., J. Hortal, and J. M. Lobo. 2005. Potential distribution modelling, niche characterization and conservation status assessment using GIS tools: a case study of Iberian Copris species. Biological Conservation 122:327-338.

Chiarucci, A., N. J. Enright, G. L. W. Perry, B. P. Miller, and B. B. Lamont. 2003. Performance of nonparametric species richness estimators in a high diversity plant community. Diversity and Distributions 9:283-295.

Church, R. L., D. M. Stoms, and F. W. Davis. 1996. Reserve selection as a maximal covering location problem. Biological Conservation 76:105-112.

Clark, F. S., and R. B. Slusher. 2000. Using spatial analysis to drive reserve design: a case study of a national wildlife refuge in Indiana and Illinois (USA). Landscape Ecology 15:75-84.

Colwell, R. K., and J. A. Coddington. 1994. Estimating terrestrial biodiversity through extrapolation. Philosophical Transactions of the Royal Society of London B 345:101-118.

Cowling, R. M., R. L. Pressey, A. T. Lombard, P. G. Desmet, and A. G. Ellis. 1999. From representation to persistence: requirements for a sustainable system of conservation areas in the species-rich Mediterranean-climate desert of southern Africa. Diversity and Distributions 5:51-71.

Cowling, R. M., R. L. Pressey, R. Sims-Castley, A. le Roux, E. Baard, C. J. Burgers, and G. Palmer. 2003a. The expert or the algorithm? - comparison of priority conservation areas in the Cape Floristic Region identified by park managers and reserve selection software. Biological Conservation 112:147-167.

Cowling, R. M., R. L. Pressey, M. Rouget, and A. T. Lombard. 2003b. A conservation plan for a global biodiversity hotspot - the Cape Floristic Region, 


\section{HORTAL AND LOBO - SYNECOLOGICAL CONSERVATION FRAMEWORK}

South Africa. Biological Conservation 112:191216.

Cowling, R. M., A. T. Knight, D. P. Faith, S. Ferrier, A. T. Lombard, A. Driver, M. Rouget, K. Maze, and P. G. Desmet. 2004. Nature conservation requires more than a passion for species. Conservation Biology 18:1674-1676.

Cushman, S. A., and K. McGarigal. 2002. Hierarchical, multi-scale decomposition of species-environment relationships. Landscape Ecology 17:637-646.

Danks, H. V. 2002. Modification of adverse conditions by insects. Oikos 99:10-24.

Dasmann, R. F. 1972. Towards a system for classifying natural regions of the world and their representation by national parks and reserves. Biological Conservation 4:247-255.

Davis, A. J., L. S. Jenkinson, J. H. Lawton, B. Shorrocks, and S. Wood. 1998a. Making mistakes when predicting shifts in species range in response to global warming. Nature 391:783-786.

Davis, A. J., J. H. Lawton, B. Shorrocks, and L. S. Jenkinson. 1998b. Individualistic species responses invalidate simple physiological models of community dynamics under global environmental change. Journal of Animal Ecology 67:600-612.

Dennis, R. L. H. 1997. An inflated conservation load for European butterflies: increases in rarity and endemism accompany increases in species richness. Journal of Insect Conservation 1:43-62.

Dennis, R. L. H. 2001. Progressive bias in species status is symptomatic of fine-grained mapping units subject to repeated sampling. Biodiversity and Conservation 10:483-494.

Dennis, R. L. H., and P. B. Hardy. 1999. Targeting squares for survey: predicting species richness and incidence of species for a butterfly atlas. Global Ecology and Biogeography 8:443-454.

Dennis, R. L. H., and C. D. Thomas. 2000. Bias in butterfly distribution maps: the influence of hot spots and recorder's home range. Journal of Insect Conservation 4:73-77.

Dennis, R. L. H., and T. G. Shreeve. 2003. Gains and losses of French butterflies: test of predictions, under-recording and regional extinction from data in a new atlas. Biological Conservation 110:131139.

Dennis, R. L. H., T. H. Sparks, and P. B. Hardy. 1999. Bias in butterfly distribution maps: the effects of sampling effort. Journal of Insect Conservation 3:33-42.

Dinerstein, E., D. M. Olson, D. J. Graham, A. L. Webster, S. A. Pimm, M. A. Bookbinder, and G. Ledec. 1995. A conservation assessment of the terrestrial ecoregions of Latin America and the Caribbean. The World Bank, Washington, D. C.
Dobson, A. P., J. P. Rodríguez, W. M. Roberts, and D. S. Wilcove. 1997. Geographic distribution of endangered species in the United States. Science 275:550-553.

Dyson, R. G. 2004. Strategic development and SWOT analysis at the University of Warwick. European Journal of Operational Research 152:631-640.

Dyson, R. G., and F. A. O'Brien 1998. Strategic Development: Methods and Models. Wiley, Chichester.

Edwards, J. L., M. A. Lane, and E. S. Nielsen. 2000. Interoperability of biodiversity databases: biodiversity information on every desktop. Science 289:2312-2314.

Elith, J., C. H. Graham, R. P. Anderson, M. Dudik, S. Ferrier, A. Guisan, R. J. Hijmans, F. Huettmann, J. R. Leathwick, A. Lehmann, J. Li, L. G. Lohmann, B. A. Loiselle, G. Manion, C. Moritz, M. Nakamura, Y. Nakazawa, J. M. M. Overton, A. T. Peterson, S. J. Phillips, K. Richardson, R. Scachetti-Pereira, R. E. Schapire, J. Soberon, S. Williams, M. S. Wisz, and N. E. Zimmermann. 2006. Novel methods improve prediction of species' distributions from occurrence data. Ecography 29:129-151.

Emerson, B. C. 2002. Evolution on oceanic islands: molecular phylogenetic approaches to understanding pattern and process. Molecular Ecology 11:951-966.

Emmerson, M., M. Bezemer, M. D. Hunter, and T. H. Jones. 2005. Global change alters the stability of food webs. Global Change Biology 11:490-501.

Engler, R., A. Guisan, and L. Rechsteiner. 2004. An improved approach for predicting the distribution of rare and endangered species from occurrence and pseudo-absence data. Journal of Applied Ecology 41:263-274.

Faith, D. P. 1994. Phylogenetic pattern and quantification of organismal biodiversity. Philosophical Transactions of the Royal Society of London B 345:45-48.

Faith, D. P., and P. A. Walker. 1996a. Environmental diversity: on the best-possible use of surrogate data for assessing the relative biodiversity set of areas. Biodiversity and Conservation 5:399-415.

Faith, D. P., and P. A. Walker. 1996b. How do indicator groups provide information about the relative biodiversity of different sets of areas?: on hotspots, complementarity and pattern-based approaches. Biodiversity Letters 3:18-25.

Faith, D. P., and S. Ferrier. 2002. Linking beta diversity, environmental variation, and biodiversity assessment. dEbate response to J. F. Duivenvoorden et al. 2002. Science 295:636b.

Faith, D. P., S. Ferrier, and P. A. Walker. 2004. The ED strategy: how species-level surrogates indicate 


\section{HORTAL AND LOBO - SYNECOLOGICAL CONSERVATION FRAMEWORK}

general biodiversity patterns through an 'environmental diversity' perspective. Journal of Biogeography 31:1207-1217.

Ferrier, S. 2002. Mapping spatial pattern in biodiversity for regional conservation planning: Where to from here? Systematic Biology 51:331-363.

Ferrier, S., and A. Guisan. 2006. Spatial modelling of biodiversity at the community level. Journal of Applied Ecology 43:393-404.

Ferrier, S., G. Watson, J. Pearce, and M. Drielsma. 2002a. Extended statistical approaches to modelling spatial pattern in biodiversity in northeast New South Wales. I. Species-level modelling. Biodiversity and Conservation 11:2275-2307.

Ferrier, S., M. Drielsma, G. Manion, and G. Watson. 2002b. Extended statistical approaches to modelling spatial pattern in biodiversity in northeast New South Wales. II. Community-level modelling. Biodiversity and Conservation 11:23092338.

Fielding, A. H. 2002. What are the appropriate characteristics of an accuracy measure? Pp. 271280 in J. M. Scott, P. J. Heglund, J. B. Haufler, M. Morrison, M. G. Raphael, W. B. Wall, and F. Samson, eds. Predicting species occurrences: Issues of accuracy and scale. Island Press, Covelo, California.

Flather, C. H., K. R. Wilson, D. J. Dean, and W. C. McComb. 1997. Identifying gaps in conservation networks: of indicators and uncertainty in geographic-based analysis. Ecological Applications 7:531-542.

Fleishman, E., and R. Mac Nally. 2003. Distinguishing between signal and noise in faunal responses to environmental change. Global Ecology and Biogeography 12:395-402.

Fleishman, E., J. R. Thomson, R. Mac Nally, D. D. Murphy, and J. P. Fay. 2005. Using indicator species to predict species richness of multiple taxonomic groups. Conservation Biology 19:11251137.

Fortin, M.-J., T. H. Keitt, B. A. Maurer, M. L. Taper, D. M. Kaufman, and T. M. Blackburn. 2005. Species' geographic ranges and distributional limits: pattern analysis and statistical issues. Oikos 108:7-17.

Galante, E., and J. R. Verdú 2000. Los Artrópodos de la "Directiva Hábitat" en España. Ministerio de Medio Ambiente, Madrid.

Gaston, K. J. 1994. Rarity. Chapman \& may, London.

Gaston, K. J. 1996. What is biodiversity? Pp. 1-9 in K. J. Gaston, ed. Biodiversity. A Biology of Numbers and Difference. Blackwell Science, Oxford.

Gaston, K. J. 2003. The structure and dynamics of geographic ranges. Oxford University Press, Oxford.
Gaston, K. J., and R. David. 1994. Hotspots across Europe. Biodiversity Letters 2:108-116.

Gaston, K. J., and A. S. L. Rodrigues. 2003. Reserve selection in regions with poor biological data. Conservation Biology 17:188-195.

Gewin, V. 2002. All living things, online. Nature 418:362-363.

Gillespie, R. G., and G. K. Roderick. 2002. Arthropods on Islands: colonization, speciation, and conservation. Annual Review of Entomology 47:595-632.

Gladstone, W. 2002. The potential value of indicator groups in the selection of marine reserves. Biological Conservation 104:211-220.

Gorshkov, V. G., A. M. Makarieva, and V. V. Gorshkov. 2004. Revising the fundamentals of ecological knowledge: the biota-environment interaction. Ecological Complexity 1:17-36.

Gotelli, N. J., and R. K. Colwell. 2001. Quantifying biodiversity: procedures and pitfalls in the measurement and comparison of species richness. Ecology Letters 4:379-391.

Graham, C. H., S. Ferrier, F. Huettman, C. Moritz, and A. T. Peterson. 2004. New developments in museum-based informatics and applications in biodiversity analysis. Trends in Ecology \& Evolution 19:497-503.

Green, R. E., A. Balmford, P. R. Crane, G. M. Mace, J. D. Reynolds, and R. K. Turner. 2005. A Framework for Improved Monitoring of Biodiversity: Responses to the World Summit on Sustainable Development. Conservation Biology 19:56-65.

$\mathrm{Gu}$, W., and R. K. Swihart. 2004. Absent or undetected? Effects of non-detection of species occurrence on wildlife-habitat models. Biological Conservation 116:195-203.

Guisan, A., and N. E. Zimmermann. 2000. Predictive habitat distribution models in ecology. Ecological Modelling 135:147-186.

Guisan, A., and J.-P. Theurillat. 2000. Equilibrium modeling of alpine plant distribution: how far can we go? Phytocoenologia 30:353-384.

Guisan, A., and W. Thuiller. 2005. Predicting species distribution: offering more than simple habitat models. Ecology Letters 8:993-1009.

Hampe, A. 2004. Bioclimate envelopes: what they detect and what they hide. Global Ecology and Biogeography 13:469-471.

Hannah, L., G. F. Midgley, and D. Millar. 2002. Climate change-integrated conservation strategies. Global Ecology and Biogeography 11:485-495.

Heikkinen, R. K., and S. Neuvonen. 1997. Species richness of vascular plants in the subarctic landscape of northern Finland: modelling 


\section{HORTAL AND LOBO - SYNECOLOGICAL CONSERVATION FRAMEWORK}

relationships to the environment. Biodiversity and Conservation 6:1181-1201.

Hengeveld, R. 1990. Dynamic Biogeography. Cambridge University Press, Cambridge.

Hewitt, G. M. 1996. Some genetic consequences of ice ages, and their role in divergence and speciation. Biological Journal of the Linnean Society 58:247276.

Hewitt, G. M. 1999. Post-glacial re-colonization of European biota. Biological Journal of the Linnean Society 68:87-112.

Hickling, R., D. B. Roy, J. K. Hill, and C. D. Thomas. 2005. A northward shift of range margins in British Odonata. Global Change Biology 11:502-506.

Higgins, J. V., T. H. Ricketts, J. D. Parrish, E. Dinerstein, G. Powell, S. Palminteri, J. M. Hoekstra, J. Morrison, A. Tomasek, and J. Adams. 2004. Beyond Noah: Saving species is not enough. Conservation Biology 18:1672-1673.

Hill, J. K., C. D. Thomas, R. Fox, M. G. Telfer, S. G. Willis, J. Asher, and B. Huntley. 2002. Responses of butterflies to twentieth century climate warming: implications for future ranges. Proceedings of the Royal Society of London B 269:2163-2171.

Hingston, R. W. G. 1932. A naturalist in the Guiana forest. Edward Arnold \& Co., London.

Hirzel, A. H. 2001. When GIS come to life. Linking landscape- and population ecology for large population management modelling: the case of Ibex (Capra ibex) in Switzerland. Page 106. Institute of Ecology, Laboratory for Conservation Biology. University of Lausanne, Lausanne.

Hirzel, A., V. Helfer, and F. Métral. 2001. Assessing habitat-suitability models with a virtual species. Ecological Modelling 145:111-121.

Hirzel, A. H., J. Hausser, D. Chessel, and N. Perrin. 2002. Ecological-niche factor analysis: How to compute habitat- suitability maps without absence data? Ecology 83:2027-2036.

Hirzel, A. H., B. Posse, P.-A. Oggier, Y. Crettenand, C. Glenz, and R. Arlettaz. 2004. Ecological requirements of a reintroduced species, with implications for release policy: the Bearded vulture recolonizing the Alps. Journal of Applied Ecology 41:1103-1116.

Hortal, J. 2004. Selección y Diseño de Áreas Prioritarias de Conservación de la Biodiversidad mediante Sinecología. Inventario y modelización predictiva de la distribución de los escarabeidos coprófagos (Coleoptera, scarabaeoidea) de Madrid. PhD Thesis. Departamento de Biología, Facultad de Ciencias. Universidad Autónoma de Madrid.

Hortal, J., and J. M. Lobo. 2005. An ED-based protocol for the optimal sampling of biodiversity. Biodiversity and Conservation 14:2913-2947.
Hortal, J., J. M. Lobo, and F. Martín-Piera. 2001. Forecasting insect species richness scores in poorly surveyed territories: the case of the Portuguese dung beetles (Col. Scarabaeinae). Biodiversity and Conservation 10:1343-1367.

Hortal, J., J. M. Lobo, and F. Martín-Piera. 2003. Una estrategia para obtener regionalizaciones bióticas fiables a partir de datos incompletos: el caso de los Escarabeidos (Coleoptera) Ibérico-Baleares. Graellsia 59:331-344.

Hortal, J., P. Garcia-Pereira, and E. García-Barros. 2004. Butterfly species richness in mainland Portugal: Predictive models of geographic distribution patterns. Ecography 27:68-82.

Hortal, J., P. A. V. Borges, and C. Gaspar. 2006. Evaluating the performance of species richness estimators: Sensitivity to sample grain size. Journal of Animal Ecology 75:274-287.

Hortal, J., P. A. V. Borges, F. Dinis, A. JiménezValverde, R. M. Chefaoui, J. M. Lobo, S. Jarroca, E. Brito de Azevedo, C. Rodrigues, J. Madruga, J. Pinheiro, R. Gabriel, F. Cota Rodrigues, and A. R. Pereira. 2005. Using ATLANTIS - Tierra 2.0 and GIS environmental information to predict the spatial distribution and habitat suitability of endemic species. Pp. 69-113 in P. A. V. Borges, R. Cunha, R. Gabriel, A. F. Martins, L. Silva, and V. Vieira, eds. A list of the terrestrial fauna (Mollusca and Arthropoda) and flora (Bryophyta, Pteridophyta and Spermatophyta) from the Azores. Direcção Regional de Ambiente and Universidade dos Açores, Horta, Angra do Heroísmo and Ponta Delgada.

Howard, P. C., P. Viskanic, T. R. B. Davenport, F. W. Kigenyi, M. Baltzer, C. J. Dickinson, J. S. Lwanga, R. A. Matthews, and A. Balmford. 1998. Complementarity and the use of indicator groups for reserve selection inUganda. Nature 394:472475.

Iverson, L. R., and A. M. Prasad. 1998a. Predicting potential future abundance of 80 tree species following climate change in the eastern United States. Ecological Monographs 68:465-485.

Iverson, L. R., and A. M. Prasad. 1998b. Estimating regional plant biodiversity with GIS modelling. Diversity and Distributions 4:49-61.

Iverson, L. R., M. W. Schwartz, and A. M. Prasad. 2004. How fast and far might tree species migrate in the eastern United States due to climate change? Global Ecology and Biogeography 13:209-219.

Jetz, W., and C. Rahbek. 2001. Geometric constraints explain much of the species richness pattern in African birds. PNAS 98:5661-5666.

Jiménez-Valverde, A., and J. Hortal. 2003. Las curvas de acumulación de especies y la necesidad de 


\section{HORTAL AND LOBO - SYNECOLOGICAL CONSERVATION FRAMEWORK}

evaluar la calidad de los inventarios biológicos. Revista Ibérica de Aracnología 8:151-161.

Kareiva, P., and M. Marvier. 2003. Conserving biodiversity coldspots. American Scientist 91:344351.

Kennedy, T. A., S. Naeem, K. M. Howe, J. M. H. Knops, D. Tilman, and P. Reich. 2002. Biodiversity as a barrier to ecological invasion. Nature 417:636638 .

Kitching, R. 2000. Biodiversity, hotspots and defiance. Trends in Ecology and Evolution 15:484-485.

Larsen, F. W., and C. Rahbek. 2005. The influence of spatial grain size on the suitability of the highertaxon approach in continental priority-setting. Animal Conservation 8:389-396.

Lawton, J. H. 1997. The science and non-science of conservation biology. Oikos 79:3-5.

Lawton, J. H. 1999. Are there general laws in ecology? Oikos 84:177-192.

Lehman, C. D., and D. Tilman. 2000. Biodiversity, stability, and productivity in competitive communities. The American Naturalist 156:534552.

Lehmann, A., J. M. Overton, and M. P. Austin. 2002a. Regression models for spatial prediction: their role for biodiversity and conservation. Biodiversity and Conservation 11:2085-2092.

Lehmann, A., J. R. Leathwick, and J. M. Overton. 2002b. Assessing New Zealand fern diversity from spatial predictions of species assemblages. Biodiversity and Conservation 11:2217-2238.

Levin, S. A. 1992. The problem of pattern and scale in ecology. Ecology 73:1943-1967.

Levine, J. M., and C. M. D'Antonio. 1999. Elton revisited: a review of evidence linking diversity and invasibility. Oikos 87:15-26.

Lewis, O. T., and S. R. Bryant. 2002. Butterflies on the move. Trends in Ecology and Evolution 17:351352.

Lobo, J. M. 2001. Decline of roller dung beetle (Scarabaeinae) populations in the Iberian peninsula during the 20th century. Biological Conservation 97:43-50.

Lobo, J. M., and G. Halffter. 2000. Biogeographical and ecologic factors affecting the altitudinal variation of mountainous communities of coprophagous beetles (Coleoptera: Scarabaeoidea): A comparative study. Annals of the Entomological Society of America 93:115-126.

Lobo, J. M., and F. Martín-Piera. 2002. Searching for a predictive model for species richness of Iberian dung beetle based on spatial and environmental variables. Conservation Biology 16:158-173.

Lobo, J. M., and J. Hortal. 2003. Modelos predictivos: Un atajo para describir la distribución de la diversidad biológica. Ecosistemas 2003/1.
Lobo, J. M., I. Castro, and J. C. Moreno. 2001. Spatial and environmental determinants of vascular plant species richness distribution in the Iberian Peninsula and Balearic Islands. Biological Journal of the Linnean Society 73:233-253.

Lobo, J. M., J. P. Lumaret, and P. Jay-Robert. 2002. Modelling the species richness of French dung beetles (Coleoptera, Scarabaeidae) and delimiting the predicitive capacity of different groups of explanatory variables. Global Ecology and Biogeography 11:265-277.

Lobo, J. M., J. R. Verdu, and C. Numa. 2006. Environmental and geographical factors affecting the Iberian distribution of flightless Jekelius species (Coleoptera: Geotrupidae). Diversity and Distributions 12:179-188.

Loiselle, B. A., C. A. Howell, C. H. Graham, C. H. Goerck, T. Brooks, K. G. Smith, and P. H. Williams. 2003. Avoiding Pitfalls of Using Species Distribution Models in Conservation Planning. Conservation Biology 17:1591-1600.

Lombard, A. T., R. M. Cowling, R. L. Pressey, and A. G. Rebelo. 2003. Effectiveness of land classes as surrogates for species in conservation planning for the Cape Floristic Region. Biological Conservation 112:45-62.

Lomolino, M. V. 2004. Conservation Biogeography. Pp. 293-296 in M. V. Lomolino, and L. R. Heaney, eds. Frontiers of Biogeography: new directions in the geography of nature. Sinauer Associates, Inc., Sunderland, Massachussets.

Loreau, M., N. Mouquet, and A. Gonzalez. 2003. Biodiversity as spatial insurance in heterogeneous landscapes. Proceedings of the National Academy of Sciences of the United States of America 100:12765-12770.

Lumaret, J. P., and J. M. Lobo. 1996. Geographic distribution of endemic dung beetles (Coleoptera, Scarabaeoidea) in the Western Palaearctic region. Biodiversity Letters 3:192-199.

Mac Nally, R., and E. Fleishman. 2004. A successful predictive model of species richness based on indicator species. Conservation Biology 18:646654.

Mac Nally, R., E. Fleishman, J. P. Fay, and D. D. Murphy. 2003. Modelling butterfly species richness using mesoscale environmental variables: model construction and validation for mountain ranges in the Great Basin of Western North America. Biological Conservation 110:21-31.

Mac Nally, R., A. F. Bennett, G. W. Brown, L. F. Lumsden, A. Yen, S. Hinkley, P. Lilywhite, and D. Ward. 2002. How well do ecosystem-based planning units represent different components of biodiversity? Ecological Applications 12:900-912. 


\section{HoRTAL AND LOBO - SYNECOLOGICAL CONSERVATION FRAMEWORK}

Mackey, B. G., H. A. Nix, M. F. Hutchinson, J. P. MacMahon, and P. E. Fleming. 1988. Assessing representativeness of places for conservation reservation and Heritage listing. Environmental Management 12:501-514.

MacKinnon, J., and K. MacKinnon. 1986a. Review of the Protected Areas System in the Afrotropical realm. IUCN, UNEP, Gland, Switzerland and Cambridge, UK.

MacKinnon, J., and K. MacKinnon. 1986b. Review of the Protected Areas System in the Indo-Malayan Realm. IUCN, UNEP, Gland, Switzerland and Cambridge, UK.

MacKinnon, J., G. Child, and J. Thorsell. 1986. Managing Protected Areas in the tropics. IUCN, Gland, Switzerland.

Margules, C. R., and R. L. Pressey. 2000. Systematic conservation planning. Nature 405:243-253.

Margules, C. R., A. O. Nicholls, and M. P. Austin. 1987. Diversity of Eucalyptus species predicted by a multi-variable environmental gradient. Oecologia 71:229-232.

Margules, C. R., A. O. Nicholls, and R. L. Pressey. 1988. Selecting Networks of Reserves to Maximise Biological Diversity. Biological Conservation 43:63-76.

Margules, C. R., A. O. Nicholls, and M. B. Usher. 1994. Apparent species turnover, probability of extinction and the selection of nature reserves: a case study of the Ingleborough limestone pavements. Conservation Biology 8:398-409.

Martínez-Meyer, E. 2005. Climate change and biodiversity: some considerations in forecasting shifts in species potential distributions. Biodiversity Informatics 2:42-55.

Martín-Piera, F. 2001. Area networks for conserving Iberian insects: A case study of dung beetles (col., Scarabaeoidea). Journal of Insect Conservation 5:233-252.

Martín-Piera, F., and J. M. Lobo. 2003. Database records as a sampling effort surrogate to predict spatial distribution of insects in either poorly or unevenly surveyed areas. Acta Entomológica Ibérica e Macaronésica 1:23-35.

Midgley, G. F., L. Hannah, D. Millar, W. Thuiller, and A. Booth. 2003. Developing regional and specieslevel assessments of climate change impacts on biodiversity in the Cape Floristic Region. Biological Conservation 112:87-97.

Molnar, J., M. Marvier, and P. Kareiva. 2004. The sum is greater than the parts. Conservation Biology 18:1670-1671.

Murguía, M., and J. L. Villaseñor. 2000. Estimating the quality of the records used in quantitative biogeography with presence-absence matrices. Annales Botanici Fennici 37:289-296.
Nicholls, A. O. 1989. How to make biological surveys go further with Generalised Linear Models. Biological Conservation 50:51-75.

Nicholls, A. O., and C. Margules. 1993. An upgraded reserve selection algorithm. Biological Conservation 64:165-169.

Nichols, W. F., K. T. Killingbeck, and P. V. August. 1998. The influence of geomorphological heterogeneity on biodiversity. II. A landscape perspective. Conservation Biology 12:371-379.

Nieto, M., M. Bastir, F. J. Cabrero-Sañudo, J. Hortal, C. Martínez-Maza, and J. Rodríguez. 2004. Does evolution evolve? Pp. 232-252. Homenaje a Emiliano Aguirre, volúmen de Paleoantropología. Museo Arqueológico Regional de Madrid, Alcalá de Henares, Madrid.

Noss, R. F. 1987. From plant communities to landscapes in conservation inventories: a look at the Nature Conservancy (USA). Biological Conservation 41:11-37.

Oliver, I., A. Holmes, J. M. Dangerfield, M. Gillings, A. J. Pik, D. R. Britton, M. Holley, M. E. Montgomery, M. Raison, V. Logan, R. L. Pressey, and A. J. Beattie. 2004. Land systems as surrogates for biodiversity in conservation planning. Ecological Applications 14:485-503.

Olson, D. M., and E. Dinerstein. 1998. The Global 2000: A representation approach to conserving the Earth's most biologically valuable ecoregions. Conservation Biology 12:502-515.

Parmesan, C., N. Ryrholm, C. Stefanescu, J. K. Hill, C. D. Thomas, H. Descimon, B. Huntley, L. Kaila, J. Kullberg, T. Tammaru, W. J. Tennent, J. A. Thomas, and M. Warren. 1999. Poleward shifts in geographical ranges of butterfly species associated with regional warming. Nature 399:579-583.

Pearson, D. L., and S. S. Carroll. 1999. The influence of spatial scale on cross-taxon congruence patterns and prediction accuracy of species richness. Journal of Biogeography 26:1079-1090.

Pearson, R. G., and T. P. Dawson. 2003. Predicting the impacts of climate change on the distribution of species: are bioclimatic envelope models useful? Global Ecology and Biogeography 12:361-371.

Pearson, R. G., and T. P. Dawson. 2004. Bioclimate envelopes: what they detect and what they hide response to Hampe (2004). Global Ecology and Biogeography 13:471-473.

Peterson, A. T., J. Soberón, and V. Sánchez-Cordero. 1999. Conservatism of ecological niches in evolutionary time. Science 285:1265-1267.

Peterson, A. T., S. L. Egbert, V. Sánchez-Cordero, and K. P. Price. 2000. Geographic analysis of conservation priority: endemic birds and mammals in Veracruz, Mexico. Biological Conservation 93:85-94. 


\section{HoRTAL AND LOBO - SYNECOLOGICAL CONSERVATION FRAMEWORK}

Peterson, A. T., E. Martínez-Meyer, C. GonzálezSalazar, and P. W. Hall. 2004. Modeled climate change effects on distributions of Canadian butterfly species. Canadian Journal of Zoology 82:851-858.

Peterson, A. T., M. A. Ortega-Huerta, J. Bartley, V. Sánchez-Cordero, J. Soberón, R. H. Buddmeier, and D. R. B. Stockwell. 2002. Future projections for Mexican faunas under global climate change scenarios. Nature 416:626-629.

Pharo, E. J., and A. J. Beattie. 2001. Management forest types as a surrogate for vascular plant, bryophyte and lichen diversity. Australian Journal of Botany 49:23-30.

Pimm, S. L., and J. H. Lawton. 1998. Planning for biodiversity. Science 279:2068-2069.

Pimm, S. L., G. J. Russell, J. L. Gittleman, and T. M. Brooks. 1995. The future of biodiversity. Science 269:347-350.

Polasky, S., J. D. Camm, A. R. Solow, B. Csuti, D. White, and R. Ding. 2000. Choosing reserve networks with incomplete species information. Biological Conservation 94:1-10.

Possingham, H. P., S. J. Andelman, M. A. Burgman, R. Medellín, L. L. Master, and D. A. Keith. 2002. Limits to the use of threatened species lists. Trends in Ecology and Evolution 17:503-507.

Powell, G. V. N., J. Barborak, and S. M. Rodriguez. 2000. Assessing representativeness of protected natural areas in Costa Rica for conserving biodiversity: a preliminary gap analysis. Biological Conservation 93:35-41.

Prendergast, J. R., R. M. Quinn, and J. H. Lawton. 1999. The gaps between theory and practice in selecting nature reserves. Conservation Biology 13:484-492.

Prendergast, J. R., R. M. Quinn, J. H. Lawton, B. C. Eversham, and D. W. Gibbons. 1993. Rare species, the coincidence of diversity hotspots and conservation strategies. Nature 365:335-337.

Pressey, R. L. 2004. Conservation planning and biodiversity: Assembling the best data for the job. Conservation Biology 18:1677-1681.

Pressey, R. L., and A. O. Nicholls. 1989. Efficiency in conservation evaluation: scoring versus iterative approaches. Biological Conservation 50:199-218.

Pressey, R. L., and R. M. Cowling. 2001. Reserve selection algorithms and the real world. Conservation Biology 15:275-277.

Pressey, R. L., C. J. Humphries, C. R. Margules, R. I. Vane-Wright, and P. H. Williams. 1993. Beyond opportunism: key principles for systematic reserve selection. Trends in Ecology and Evolution 8:124128.

Pressey, R. L., H. P. Possingham, and C. R. Margules. 1996. Optimality in reserve selection algorithms: when does it matter and how much? Biological Conservation 76:259-267.

Pyke, C. R., and D. T. Fischer. 2005. Selection of bioclimatically representative biological reserve systems under climate change. Biological Conservation 121:429-441.

Raxworthy, C. J., E. Martínez-Meyer, N. Horning, R. A. Nussbaum, G. E. Schneider, M. A. Ortega-Huerta, and A. T. Peterson. 2003. Predicting distributions of known and unknown reptile species in Madagascar. Nature 426:837-841.

Rodrigues, A. S. L., and K. J. Gaston. 2002. Optimisation in reserve selection procedures - why not? Biological Conservation 107:123-129.

Rodrigues, A. S. L., S. J. Andelman, M. I. Bakarr, L. Boitani, T. M. Brooks, R. M. Cowling, L. D. C. Fishpool, G. A. B. da Fonseca, K. J. Gaston, M. Hoffman, J. Long, P. A. Marquet, J. D. Pilgrim, R. L. Pressey, J. Schipper, W. Sechrest, S. N. Stuart, L. G. Underhill, R. W. Waller, M. E. J. Watts, and X. Yan. 2003. Global Gap Analysis: towards a representative network of protected areas. Advances in Applied Biodiversity Science 5:100.

Rodríguez, J. 1999. Use of cenograms in mammalian palaeoecology. A critical review. Lethaia 32:331347.

Rodríguez, J. 2004. Stability in Pleistocene Mediterranean mammalian communities. Palaeogeography, Palaeoclimatology, Palaeoecology 207:1-22.

Rodríguez, J. 2006. Structural continuity and multiple alternative stable states in Middle Pleistocene European mammalian communities. Palaeogeography, Palaeoclimatology, Palaeoecology 239:355-373.

Rodríguez, J., and M. Nieto. 2003. Influencia paleoecológica en mamíferos cenozoicos: limitaciones metodológicas. Coloquios de Paleontología Vol. Ext. 1:459-474.

Rojas-Soto, O. R., O. Alcantara-Ayala, and A. G. Navarro. 2003. Regionalization of the avifauna of the Baja California Peninsula, Mexico: a parsimony analysis of endemicity and distributional modelling approach. Journal of Biogeography 30:449-461.

Russell, A. F., L. L. Sharpe, P. N. M. Brotherton, and T. H. Clutton-Brock. 2003. Cost minimization by helpers in cooperative vertebrates. Proceedings of the National Academy of Sciences of the United States of America 100:3333-3338.

Saetersdal, M., I. Gjerde, and H. H. Blom. 2005. Indicator species and the problem of spatial inconsistency in nestedness patterns. Biological Conservation 122:305-316.

Sánchez-Cordero, V., V. Cirelli, M. Munguial, and S. Sarkar. 2005. Place prioritization for biodiversity 


\section{HoRTAL AND LOBO - SYNECOLOGICAL CONSERVATION FRAMEWORK}

content using species ecological niche modeling. Biodiversity Informatics 2:11-23.

Sarkar, S., J. Justus, T. Fuller, C. Kelley, J. Garson, and M. Mayfield. 2005. Effectiveness of environmental surrogates for the selection of conservation area networks. Conservation Biology 19:815-825.

Sax, D. F. 2002. Equal diversity in disparate species assemblages: a comparison of native and exotic woodlans in California. Global Ecology and Biogeography 11:49-57.

Scholes, R. J., and R. Biggs. 2005. A biodiversity intactness index. Nature 434:45-49.

Scott, J. M., P. J. Heglund, J. B. Haufler, M. Morrison, M. G. Raphael, W. B. Wall, and F. Samson, eds. 2002. Predicting species occurrences: Issues of accuracy and scale. Island Press, Covelo, California.

Segurado, P., and M. B. Araújo. 2004. An evaluation of methods for modelling species distributions. Journal of Biogeography 31:1555-1568.

Sentís, C. 2002. Retrovirus endógenos humanos: Significado biológico e implicaciones evolutivas. ARBOR 677:135-166.

Seoane, J., L. M. Carrascal, C. L. Alonso, and D. Palomino. 2005. Species-specific traits associated to prediction errors in bird habitat suitability modelling. Ecological Modelling 185:299-308.

Simberloff, D. 1998. Flagships, umbrellas and keystones: is single-species management passé in the landscape era? Biological Conservation 83:247257.

Skov, F., and J.-C. Svenning. 2004. Potential impact of climatic change on the distribution of forest herbs in Europe. Ecography 27:366-380.

Soberón, J., and J. Llorente. 1993. The use of species accumulation functions for the prediction of species richness. Conservation Biology 7:480-488.

Soberón, J., and A. T. Peterson. 2005. Interpretation of models of fundamental ecological niches and species' distribution areas. Biodiversity Informatics 2:1-10.

Sparks, T. H., D. B. Roy, and R. L. H. Dennis. 2005. The influence of temperature on migration of Lepidoptera into Britain. Global Change Biology 11:507-514.

Spector, S. 2002. Biogeographic crossroads as priority areas for conservation. Conservation Biology 16:1480-1487.

Srivasta, D. S., and J. H. Lawton. 1998. Why more productive sites have more species: An experimental test of theory using tree-hole communities. The American Naturalist 152:510529 .

Stockwell, D. R. B., and A. T. Peterson. 2002. Effects of sample size on accuracy of species distribution models. Ecological Modelling 148:1-13.
Su, J. C., D. B. Debinski, M. E. Jakubauskas, and K. Kindscher. 2004. Beyond species richness: community similarity as a measure of cross-taxon congruence for coarse-filter conservation. Conservation Biology 18:167-173.

Ter Steege, H., N. Pitman, D. Sabatier, H. Castellanos, P. Van Der Hout, D. C. Daly, M. Silveira, O. Phillips, R. Vasquez, T. Van Andel, J. Duivenvoorden, A. A. De Oliveira, R. Ek, R. Lilwah, R. Thomas, J. Van Essen, C. Baider, P. Maas, S. Mori, J. Terborgh, P. Núñez Vargas, H. Mogollón, and W. Morawetz. 2003. A spatial model of tree $\square$-diversity and tree density for the Amazon. Biodiversity and Conservation 12:22552277.

Thomas, C. D., and J. J. Lennon. 1999. Birds extend their ranges northwards. Nature 399:213.

Thomas, C. D., E. J. Bodsworth, R. J. Wilson, A. D. Simmons, Z. G. Davies, M. Musche, and L. Conradt. 2001. Ecological and evolutionary processes at expanding range margins. Nature 411:577-581.

Thomas, C. D., A. Cameron, R. E. Green, M. Bakkenes, L. J. Beaumont, Y. C. Collingham, B. F. N. Erasmus, M. F. de Siqueira, A. Grainger, L. Hannah, L. Hughes, B. Huntley, A. S. van Jaarsveld, G. F. Midgley, L. Miles, M. A. OrtegaHuerta, A. T. Peterson, O. L. Phillips, and S. E. Williams. 2004. Extinction risk from climate change. Nature 427:145-148.

Thomson, J. R., E. Fleishman, R. M. Nally, and D. S. Dobkin. 2005. Influence of the temporal resolution of data on the success of indicator species models of species richness across multiple taxonomic groups. Biological Conservation 124:503-518.

Thuiller, W., L. Brotons, M. B. Araújo, and S. Lavorel. 2004a. Effects of restricting environmental range data to project current and future species distributions. Ecography 27:165-172.

Thuiller, W., M. B. Araujo, R. G. Pearson, R. J. Whittaker, L. Brotons, and S. Lavorel. 2004b. Biodiversity conservation - Uncertainty in predictions of extinction risk. Nature 430: doi:10.1038/nature02716.

Tilman, D. 1999. The ecological consequences of changes in biodiversity: a search for general principles. Ecology 80:1455-1474.

Tilman, D. 2000. Causes, consequences and ethics of biodiversity. Nature 405:208-211.

Tilman, D. 2001. An evolutionary approach to ecosystem functioning. Proceedings of the National Academy of Sciences of the USA 98:10979-10980.

Tilman, D., and S. W. Pacala. 1993. The maintenance of species richness in plant communities in R. E. Ricklefs, and D. Schluter, eds. Species Diversity in Ecological Communities. Historical and 


\section{HORTAL AND LOBO - SYNECOLOGICAL CONSERVATION FRAMEWORK}

Geographical Perspectives. The University of Chicago Press, Chicago.

Tilman, D., D. Wedin, and J. Knops. 1996. Productivity and sustainability influenced by biodiversity in grassland ecosystems. Nature 379:718-720.

Tilman, D., J. Knops, D. Wedin, P. Reich, M. Ritchie, and E. Siemann. 1997a. The influence of functional diversity and composition on ecosystem processes. Science 277:1300-1302.

Tilman, D., S. Naeem, J. Knops, P. Reich, E. Siemann, D. Wedin, M. Ritchie, and J. Lawton. 1997b. Biodiversity and ecosystem properties. Science 278:1865c.

Tilman, D., P. B. Reich, and J. M. H. Knops. 2006. Biodiversity and ecosystem stability in a decadelong grassland experiment. Nature 441:629-632.

Tognelli, M. F. 2005. Assessing the utility of indicator groups for the conservation of South American terrestrial mammals. Biological Conservation 121:409-417.

Tognelli, M. F., and D. A. Kelt. 2004. Analysis of determinants of mammalian species richness in South America using spatial autoregressive models. Ecography 27:427-436.

Tognelli, M. F., C. Silva-García, F. A. Labra, and P. A. Marquet. 2005. Priority areas for the conservation of coastal marine vertebrates in Chile. Biological Conservation 126:420-428.

van Jaarsveld, A. S., S. Freitag, S. L. Chown, C. Muller, S. Koch, H. Hull, C. Bellamy, M. Krüger, S. Endrödy-Younga, M. W. Mansell, and C. H. Scholtz. 1998. Biodiversity assessment and conservation strategies. Science 279:2106-2108.

Vane-Wright, D. 1996. Identifying priorities for the conservation of biodiversity. Pp. 309-344 in K. J. Gaston, ed. Biodiversity. A biology of numbers and difference. Blackwell Science, Oxford.

Vane-Wright, R. I., C. J. Humphries, and P. H. Williams. 1991. What to protect?-Systematics and the agony of choice. Biological Conservation 55:235-254.

Venevsky, S., and I. Venevskaia. 2005. Hierarchical systematic conservation planning at the national level: Identifying national biodiversity hotspots using abiotic factors in Russia. Biological Conservation 124:235-251.

Walther, G. R., E. Post, P. Convey, A. Menzel, C. Parmesan, T. J. C. Beebee, J. M. Fromentin, O. Hoegh-Guldberg, and F. Bairlein. 2002. Ecological responses to recent climate change. Nature 416:389-395.

Ward, T. J., M. A. Vanderklift, A. O. Nicholls, and R. A. Kenchington. 1999. Selecting marine reserves using habitats and species assemblages as surrogates for biological diversity. Ecological Applications 9:691-698.
Wardle, D. A., O. Zackrisson, G. Hörnberg, and C. Gallet. 1997. Biodiversity and ecosystem properties. Science 278:1865c.

Warren, M. S., J. K. Hill, J. A. Thomas, J. Asher, R. Fox, B. Huntley, D. B. Roy, M. G. Telfer, S. Jeffcoate, P. Harding, G. Jeffcoate, S. G. Willis, J. N. Greatorex-Davies, D. Moss, and C. D. Thomas. 2001. Rapid responses of British butterflies to opposing forces of climate and habitat change. Nature 411:65-69.

Wessels, K. J., S. Freitag, and A. S. van Jaarsveld. 1999. The use of land facets as biodiversity surrogates during reserve selection at a local scale. Biological Conservation 89:21-38.

Whittaker, R. J. 1998. Island Biogeography. Ecology, Evolution and Conservation. Oxford University Press, Oxford.

Whittaker, R. J., M. B. Araújo, P. Jepson, R. J. Ladle, J. E. M. Watson, and K. J. Willis. 2005. Conservation Biogeography: assessment and prospect. Diversity and Distributions 11:3-23.

Williams, P. H. 1999. WORLDMAP 4.1 WINDOWS. Software and user document 4. Privately distributed, London.

Williams, P. H., and C. J. Humphries. 1994. Biodiversity, taxonomic relatedness, and endemism in conservation. Pp. 269-287 in P. L. Forey, C. J. Humphries, and R. I. Vane-Wright, eds. Systematics and Conservation Evaluation. Clarendon Press, Oxford.

Williams, P. H., N. D. Burgess, and C. Rahbek. 2000. Flagship species, ecological complementarity and conserving the diversity of mammals and birds in sub-Saharan Africa. Animal Conservation 3:249260.

Willis, K. J., and R. J. Whittaker. 2002. Species diversity - Scale matters. Science 295:1245-1248.

Wilson, E. O. 2002. The Future of Life. Alfred A. Knopf, New York.

Woodward, F. I., and D. J. Beerling. 1997. The dynamics of vegetation change: health warnings for equilibrium 'dodo' models. Global Ecology and Biogeography Letters 6:413-418.

Yachi, S., and M. Loreau. 1999. Biodiversity and ecosystem productivity in a fluctuating environment: The insurance hypothesis. Proceedings of the National Academy of Sciences of the United States of America 96:1463-1468.

Zimmermann, N. E., and F. Kienast. 1999. Predictive mapping of alpine grasslands in Switzerland: species versus community approach. Journal of Vegetation Science 10:469-482. 